\title{
Self-serving social strategies: A systematic review of social cognition in narcissism
}

\author{
Clare M. Eddy ${ }^{1}$ iD \\ Accepted: 19 March 2021 / Published online: 1 May 2021 \\ (C) The Author(s) 2021
}

\begin{abstract}
Narcissistic Personality Disorder is characterised by inflated self-importance, an excessive need for admiration, and a lack of empathy. The interpersonal difficulties associated with narcissistic personality may be becoming more widespread given its increasing prevalence within the general population. This systematic review investigated the relationship between narcissistic personality traits and social cognition (i.e. theory of mind; emotion recognition; empathy; emotional intelligence) in clinical and non-clinical samples. Cognitive empathy (i.e. perspective taking) appears unlikely to be impaired, while affective empathy (relating to another's emotion state) may be reduced in association with narcissism. Those with grandiose narcissism rate their empathic skills more highly than those with vulnerable narcissism, but concurrent administration of objective measures is rare, limiting insight into the validity of self-ratings. Rather than deficits in aspects of social cognition, the overall pattern could reflect motivation, or advantageous use of social cognitive skills to serve the self. Indeed, interpersonal strategies associated with narcissism (e.g. deception; manipulation) suggest the application of understanding another's beliefs or desires in the context of low empathy. Further research should seek to explore performance on a wider range of emotion recognition and theory of mind tasks, and whether characteristics such as excessive jealousy and paranoia could reflect hyper-mentalizing.
\end{abstract}

Keywords Empathy $\cdot$ Emotion recognition $\cdot$ Narcissism $\cdot$ Narcissistic personality disorder $\cdot$ Social cognition $\cdot$ Theory of mind

\section{Introduction}

Narcissistic personality (NP) is characterised by grandiosity, attention seeking, a need for admiration, and a lack of empathy. While such traits occur at varying strengths throughout the general population (e.g. Krizan \& Herlache, 2018), at the more severe end of the spectrum, this personality style can be associated with functional impairment in areas such as maintaining work and personal relationships (Stinson et al., 2008). Consequently, the definition of pathological narcissism i.e. Narcissistic Personality Disorder (NPD), entered into DSM5 (American Psychiatric Association, 2013), with diagnostic criteria referring to difficulties with personality involving impairments in self (identity; self-direction) and interpersonal (empathy; intimacy) functioning. The prevalence of more prominent NP within the general population is thought to be

Clare M. Eddy

clare.eddy1@nhs.net; c.eddy@bham.ac.uk

1 National Centre for Mental Health, Birmingham, and College of Medical and Dental Sciences, BSMHFT and University of Birmingham, Birmingham, UK rising (Twenge \& Foster, 2010) and a large proportion of the research into this personality style has been conducted in samples of individuals with milder traits. Popular assessments of NP include dimensions such as leadership/authority, grandiose exhibitionism and entitlement/exploitativeness (Ackerman et al., 2011) or grandiose/vulnerable narcissism (Pincus et al., 2009). However, our conceptualization of narcissism continues to evolve. For example, while one study using the Five Factor Narcissism Inventory (Glover et al., 2012) suggested that a three-factor model involving agentic extraversion, narcissistic neuroticism, and self-centred antagonism is the most parsimonious conceptualization (Miller et al., 2016), another recent study using the Narcissistic Personality Inventory (NPI: Raskin \& Hall, 1979) proposed five dimensions: manipulativeness; superiority; leadership/ authority; vanity and grandiose fantasies (Brown et al., 2020).

More broadly identified Narcissistic characteristics include vulnerable self-esteem, feelings of inferiority, emptiness, and boredom (Caligor et al., 2015). Some of these less obvious signs help us to understand the behavioral distinction made between grandiose (overt) and vulnerable (covert) narcissism. While both subgroups share conflicting feelings of grandiosity and vulnerability, grandiose narcissism (GN) is characterized 
by more prominent grandiosity, a sense of entitlement and self-absorption, whereas vulnerable narcissism (VN) shows more evidence of hypersensitivity, vulnerability, shyness and distress (Caligor et al., 2015; Wink, 1991). The picture can be further complicated by combinations of GN and VN traits within an individual, or fluctuation between these kinds of patterns (Oltmanns \& Widiger, 2018). Miller et al. (2016) suggest that antagonism (entitlement, arrogance, manipulativeness/exploitation) represents the core of $\mathrm{NP}$, and that the presence of high exhibitionism versus neuroticism is likely to diverge in cases of GN versus VN.

Many people with NP are highly functioning individuals. Their confidence can be attractive (Back et al., 2010), and high self-efficacy combined with a competitive nature yield professional and personal achievements (Onley et al., 2013; Sabouri et al., 2016). Some successes may arise through successful manipulation of others to gain opportunity and status. The darker side of NP includes a tendency to objectify (LachowiczTabaczek et al., 2019) or derogate (Park \& Colvin, 2015) others, self-centredness (Ronningstam, 2010) and exploitative behavior that may arise in association with impaired empathic ability (Gunderson \& Ronningstam, 2001). In pathological cases, difficulties within relationships reflect domineering, vindictive and intrusive behavior (Ogrodniczuk et al., 2009) and the impact on families, friends, colleagues and romantic partners can be profound (Miller et al., 2007). However, not all of the characteristics associated with narcissism point to a simple lack of social reasoning. Motivation is important to consider, and empathic functioning may vary according to narcissistic subtype (BaskinSommers et al., 2014).

It is thought that narcissism is associated with a poorly developed or fragile self-concept (Fukushima \& Hosoe, 2011), and that grandiose and excessive self-serving behaviors may buffer an inflated sense of self-esteem, which in turn may protect against breakdown of the self. Feelings about oneself can influence social cognition, as we often use ourselves as a starting point when reasoning about the mental states and behaviors of others (Meltzoff, 2007). In addition, some social cognitive processes which help us to understand others (such as mirroring or emotion contagion) require self-other distinction (Eddy, 2018) which could be compromised in individuals with a weakened self-concept. Ronningstam (2010) suggests that the social interactions of those with narcissism can be influenced by poor self-other distinction, perhaps helping to explain why their descriptions of close others are often vague, and centre on similarities and differences to themselves (Caligor et al., 2015). Given that individuals with narcissism may struggle to define others without referring to their own character during that process, and NPD DSM-5 criteria refer to "excessive reference to others for self-definition", there is likely to be a lack of independence pertaining to the constructs for self and other.
In summary, many NP traits are inherently interpersonal and manifest within a social context (e.g. grandiosity and exploitative-ness). Therapeutic intervention for NPD is hampered by interpersonal difficulties (Magidson et al. 2012) and high drop-out (Ogrodniczuk et al., 2009). Understanding more about social cognition in narcissism could offer important insight needed in order to make therapeutic breakthrough in pathological cases. The aims of this systematic review were to investigate patterns in performance across tasks purported to assess social cognition, across a range of tasks involving empathy, and/or recognising or reasoning about mental states, determining both strengths and weaknesses associated with narcissism (from subclinical traits to NPD). Relationships between identified social cognitive profiles, common subtypes ( $\mathrm{GN}$ and $\mathrm{VN}$ ), and more specific narcissistic traits and behaviors were explored, with a view to generating new hypotheses and recommendations for future research.

\section{Materials and Methods}

A Web Of Science (core) and Medline search was conducted on 05/06/2020 for journal articles in English, involving humans, published between 1990 and 2020, using: $\mathrm{TS}=($ Narcissis $*)$ AND TS $=($ social cognition OR empathy OR theory of mind). Filtering for social sciences and English language generated 482 items. Abstracts were screened and records were excluded if there were no human participants, original data was not reported (e.g. reviews; theory papers etc.) there was no focus on NP in either a clinical or non-clinical sample (i.e. no specific measure included) or no appropriate social cognitive measure. This phase 1 search indicated that study tasks were usually purported to measure Theory of Mind (ToM), basic emotion recognition, trait empathy or emotional intelligence. ToM refers to the ability to understand other people's mental states such as beliefs, desires and intentions (Premack \& Woodruff, 1978) e.g. through abstract perspective taking in response to written stories, whereas basic emotion recognition skills allow one to interpret visual emotional cues such as facial expressions. Empathy may be described as the ability to relate to another person's emotional state, although this could be done on an affective level e.g. through simulation or imitation of an observed emotion by oneself, or on a cognitive level i.e. a process more akin to ToM (see Shamay-Tsoory et al., 2009). Emotional intelligence involves applying social cognitive processes to effectively understand and respond to others' emotional states and to manage one's own emotional states (see Mayer \& Salovey, 1997). It was decided to include studies referring to any of these four topics given that ToM and emotion recognition may contribute to empathy and emotional intelligence as expressed in everyday life, and to include both objective and subjective measures of social cognition (i.e. ToM and emotion 
recognition tend to be assessed through experimental tasks, whereas trait empathy and emotional intelligence are often measured through self-report scales). The search uncovered some studies using imitation tasks (requiring participants to observe and imitate another's movements, or suppress imitation of observed movements), and it was decided to also include these given that a category of 'motor empathy' has been suggested (Preston \& De Waal, 2002). Some studies uncovered by the search explored emotional reactivity without an interpersonal or social cognitive element (e.g. mood fluctuations within an individual), and these were not included. In the second phase, full-texts were checked to ensure there was some examination of the direct relationship between social cognitive factors and narcissism, articles were excluded where appropriate tasks (as explained previously) were not utilised. To ensure as many relevant articles were identified as possible, the introduction and discussion of articles retained from the original database search were checked for further relevant studies. This resulted in an additional 18 papers being screened, 9 of which were included in the final set of 62 (Please see Supplementary Fig. 1. for full search and exclusions). Where individual experiments were reported within a study, details from individual experiments were included following the same criteria as for studies. Studies were grouped according to social cognitive domain, and to offer further insight, were also compared in relation to study characteristics such as participant population pool, gender balance, $\mathrm{NP}$ measures and the use of self-report versus more objective measures.

\section{Results}

\section{Study Design}

The vast majority of studies drew from the general population, but many relied on student samples (23/62). Just ten of 62 focused exclusively on specific groups such as diagnosed personality disorders (shown in the upper part of Table 1), most frequently NPD and/or Borderline Personality Disorder (BPD). A small number explored the dark triad in general (i.e. psychopathy; machiavellianism; narcissism), sometimes leading to difficulties disentangling effects related to narcissism from psychopathy, and a couple explored NP in children, especially in relation to bullying behavior. There were also a handful that explored aspects of NP in forensic populations. In these cases it was difficult to generalise to the wider NP population. Other limitations included a gender imbalance with less than 50\% male participants in 56/62 studies, and many studies only included self-report measures (23/62). In sum, research appears to be predominantly assessing the milder, and occasionally the more severe and complex end of the spectrum, with fewer studies focused on NPD or more severe narcissistic traits in samples with limited comorbidity.

For measuring narcissism, the NPI (Raskin \& Hall, 1979) was the most popular measure, used in 34 of the 62 studies, sometimes in short form. This scale tends to measure traits now more associated with the grandiose side of narcissism (e.g. showing off; feeling very competent; enjoying power and compliments; expecting things from other people). The next most frequently utilised was the Hyper-Sensitive Narcissism Scale (8/62; HSNS: Hendin \& Cheek, 1997), which focuses more on traits associated with $\mathrm{VN}$ e.g. taking things personally; feeling self-conscious; being more emotionally affected by slighting remarks. The Dark Triad Dirty Dozen (DTDD: Jonason \& Webster, 2010) which focuses on attention, admiration, status, and favour in relation to narcissism, and also appears to cover aspects of VN (e.g. Dinić et al., 2018), was used by a similar proportion (6/62 studies). A few studies used measures such as the Pathological Narcissism Inventory (PNI: Pincus et al., 2009) which assesses features associated with GN (e.g. domineering; intrusive) and VN (e.g. avoidant; exploitable interpersonal issues); the Narcissistic Admiration and Rivalry Questionnaire (NARQ: Back et al., 2013); or the Short Dark Triad (SD3: Jones \& Paulhus, 2014), a more recently developed measure. Other scales included clinical assessments for more general use in Psychiatry (Table 1).

In relation to social cognition, empathy was explored far more than either ToM or emotion recognition, with related tasks used by 41 of the 62 studies. Of these, 22 studies included the Interpersonal Reactivity Index (Davis, 1983), a selfreport scale measuring empathy in terms of perspective taking (PT: adopting the perspective of others), empathic concern (EC: relating to others' emotions), fantasy (imagining being characters from fiction) and personal distress (PD: being distressed when another person is in crisis). Cognitive empathy (i.e. the ability to imagine another's point of view) may be assessed using the PT and sometimes also the fantasy subscales, while affective empathy (relating to another's emotion state) may be assessed by using the EC and perhaps also the PD subscale. Some studies only used the PT and EC subscales as measures of cognitive and affective empathy, respectively. A smaller number of studies used the Empathy Quotient (6 studies; EQ: Baron-Cohen \& Wheelwright, 2004) and the Basic Empathy Scale (4 studies; BES: Jolliffe \& Farrington, 2006). Emotional Intelligence scales were the next most common type of measure (14 studies), the most popular being the Trait Emotional Intelligence Questionnaire (TEIQ: Petrides \& Furnham, 2006) used in 5 studies.

Emotion recognition was explored infrequently (13 studies), often using facial expressions of basic emotions (Table 1). However, 7 studies employed the Reading the Mind in the Eyes Test (RMET: Baron-Cohen et al., 2001) 


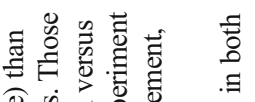

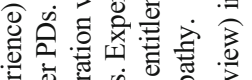

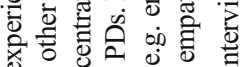

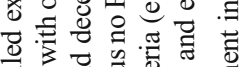

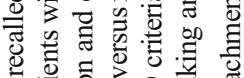

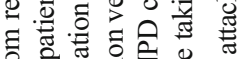

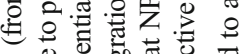

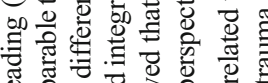

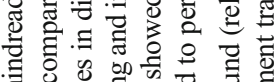

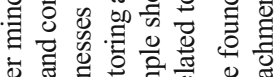

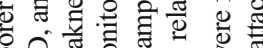

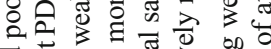

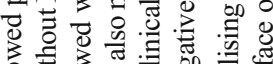

क

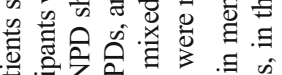

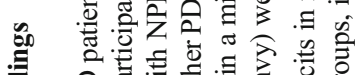

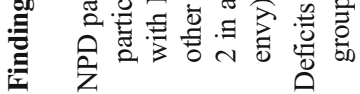

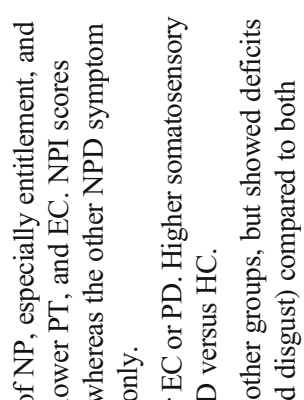

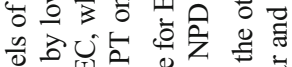

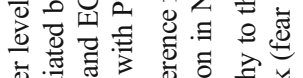

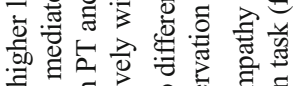

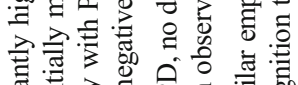
1

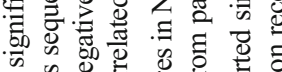

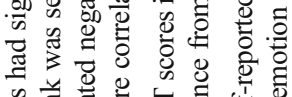

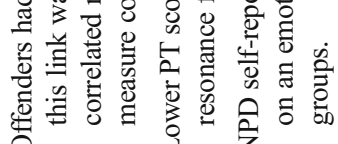

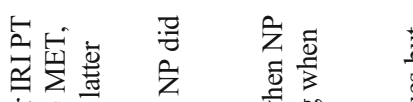

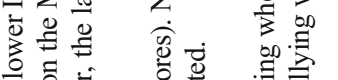

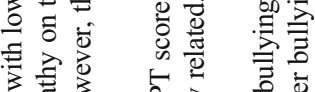

产

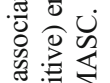

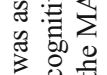

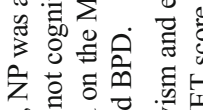

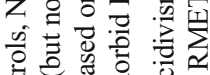

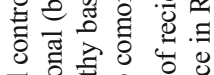

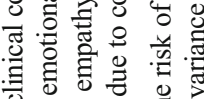

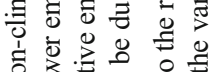

0
0
0
0

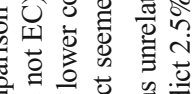

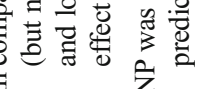

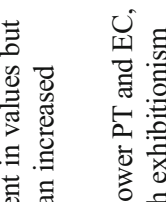

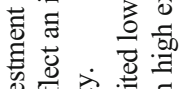

它总总声

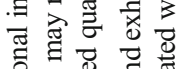

을. 品

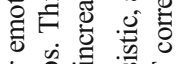

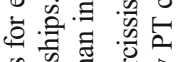

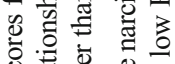

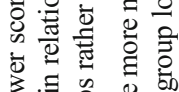

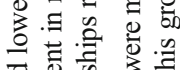

可

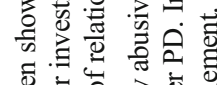

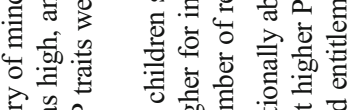

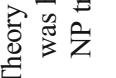

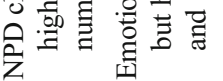

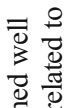

응

氹

矛 药

当

요

중휴

要

营

궁

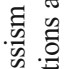

氙

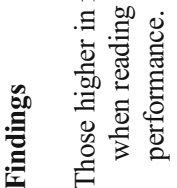

ฮั

晨

衰

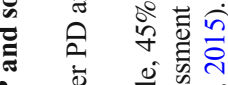

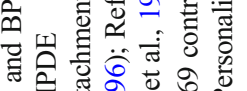

.

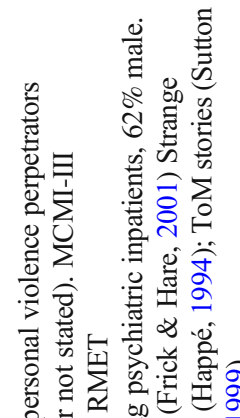

离 $\quad \dot{0}$

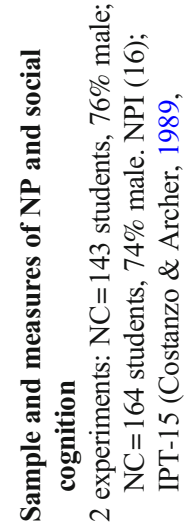

- 0 है

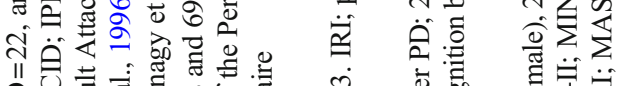

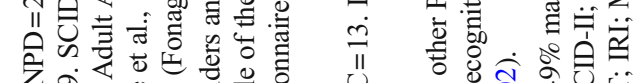

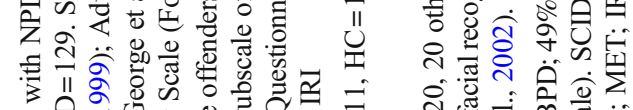

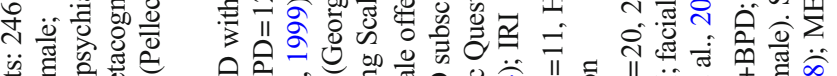

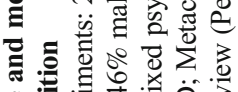

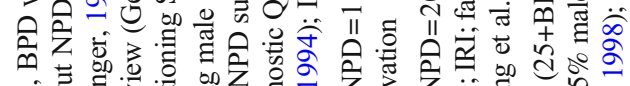

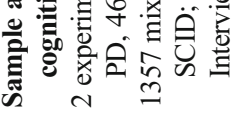

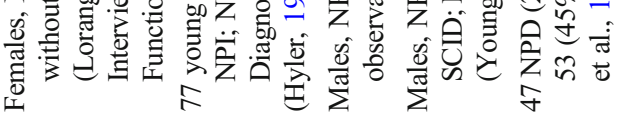

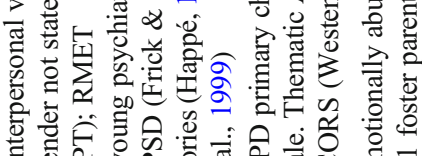

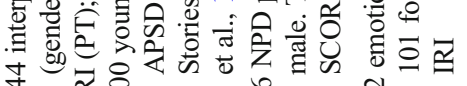

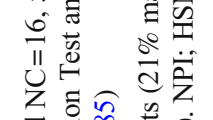

产

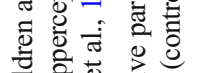

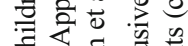

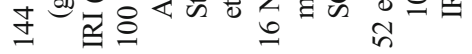
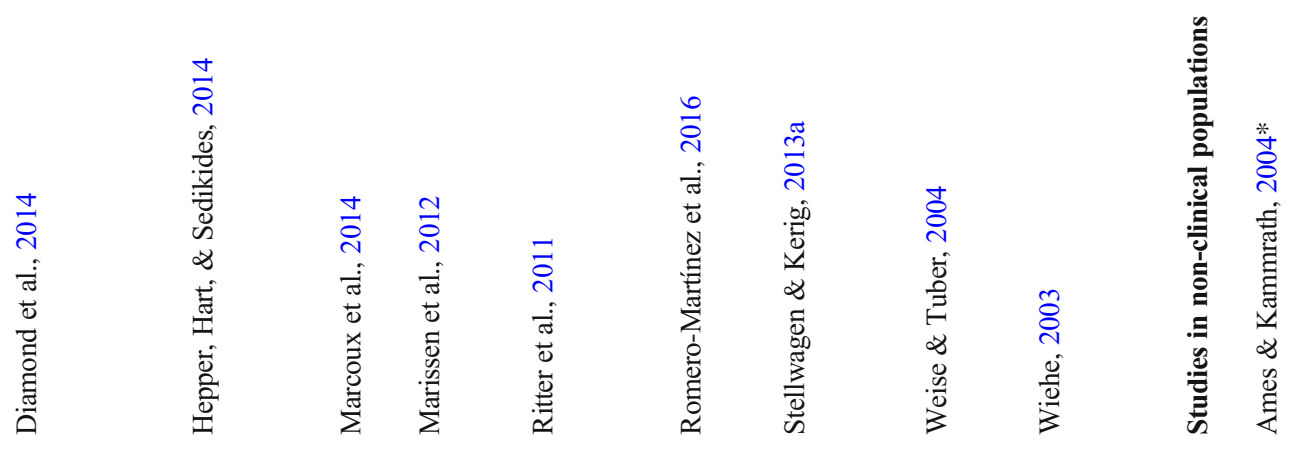

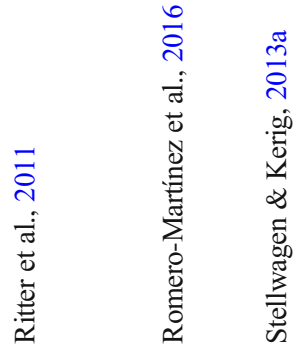

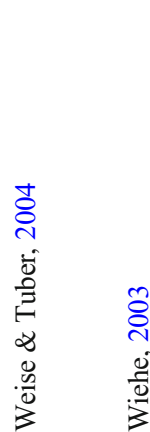
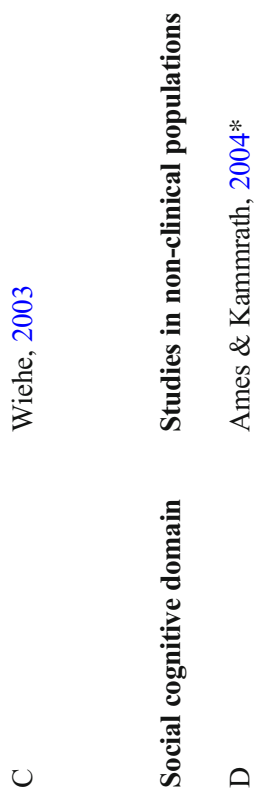

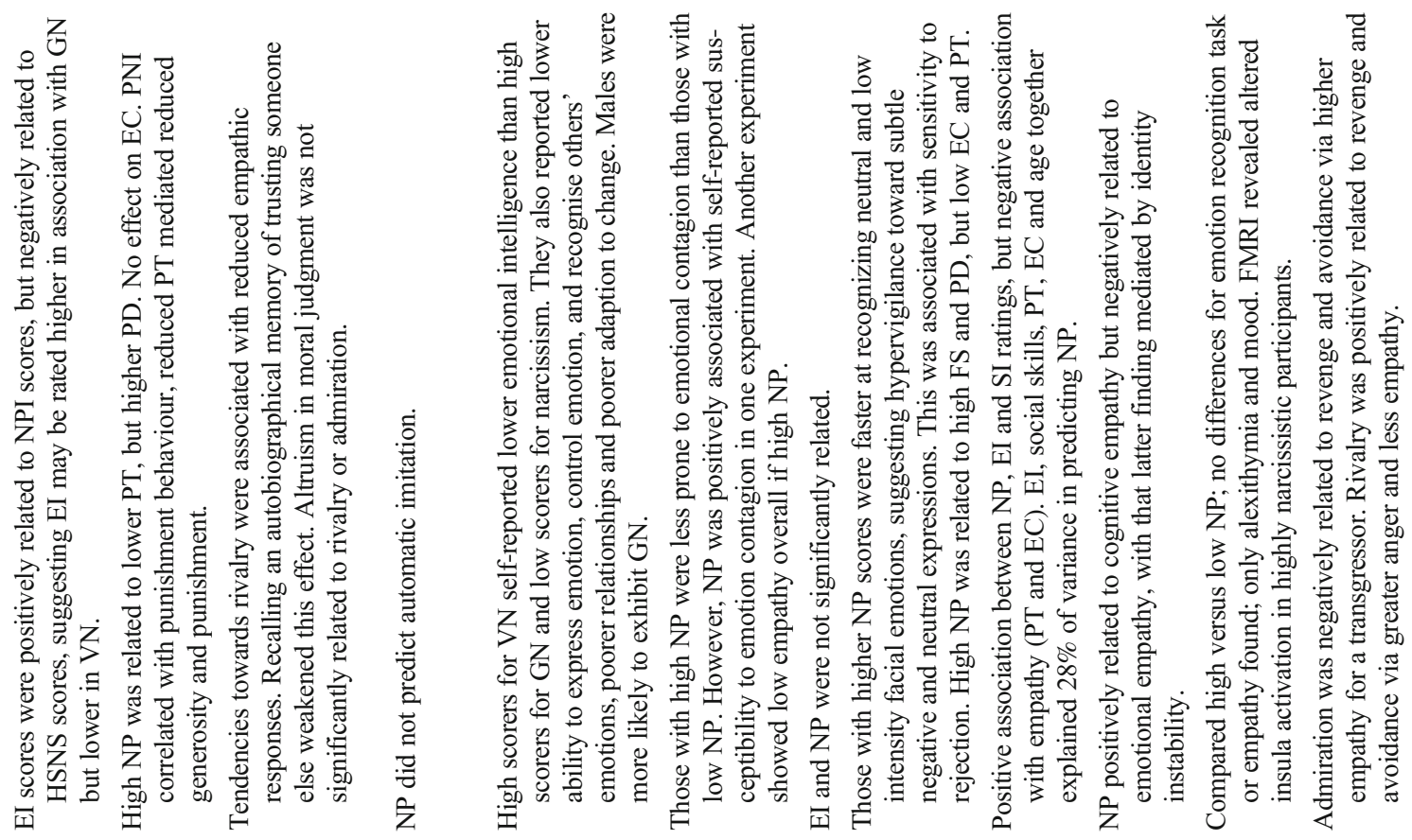

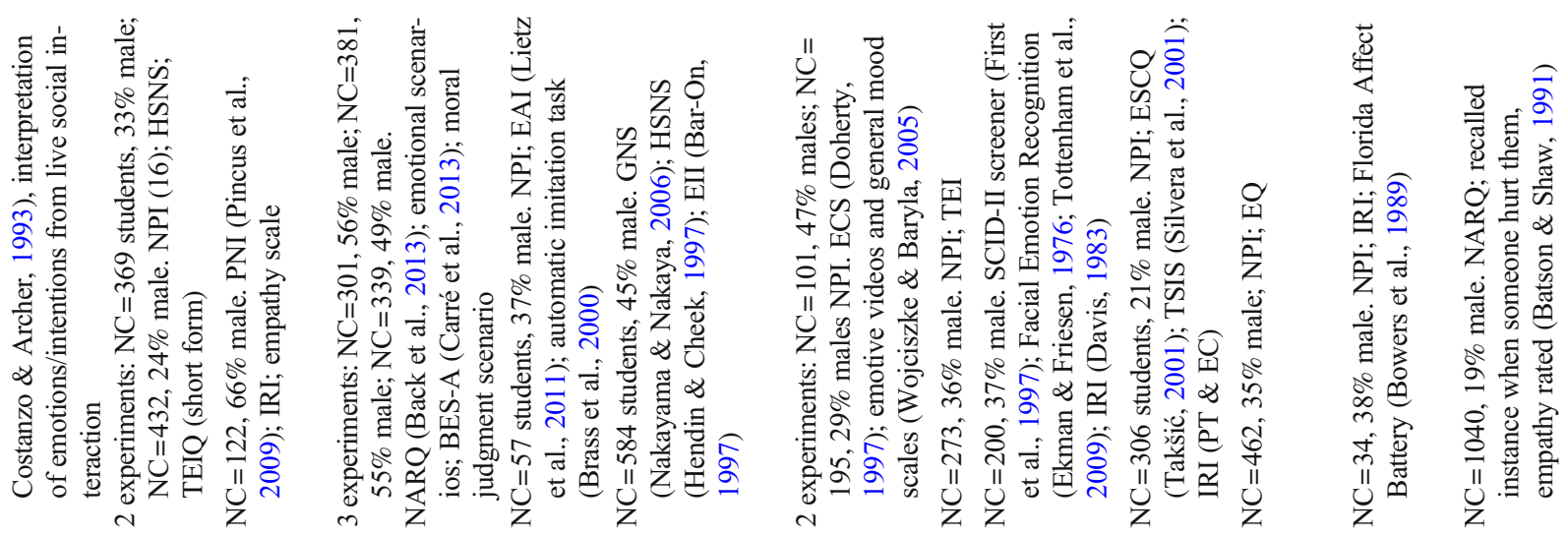

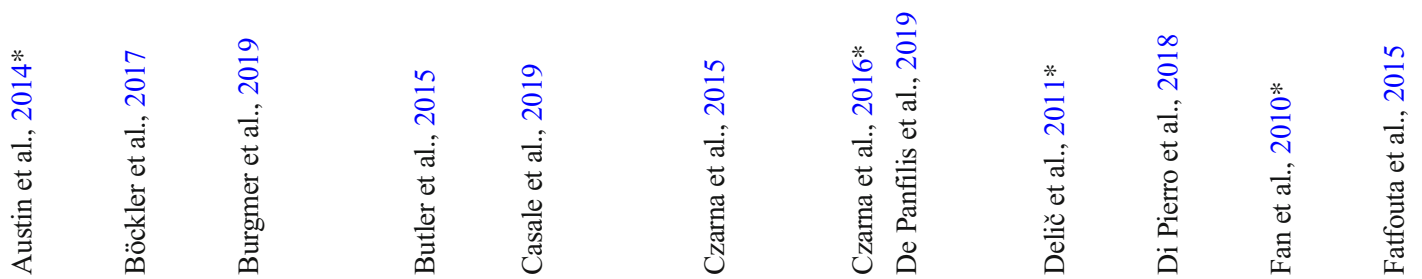



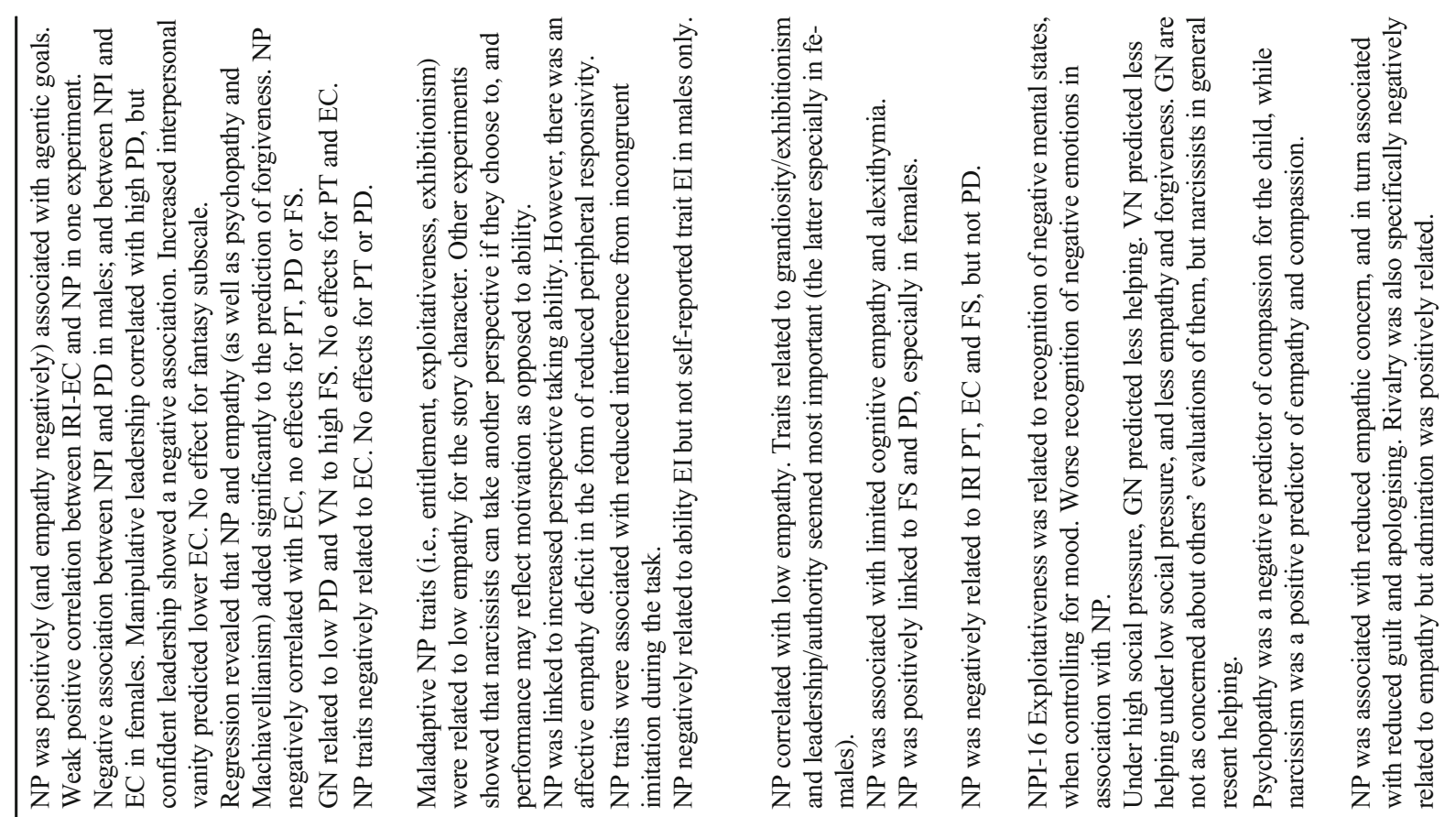

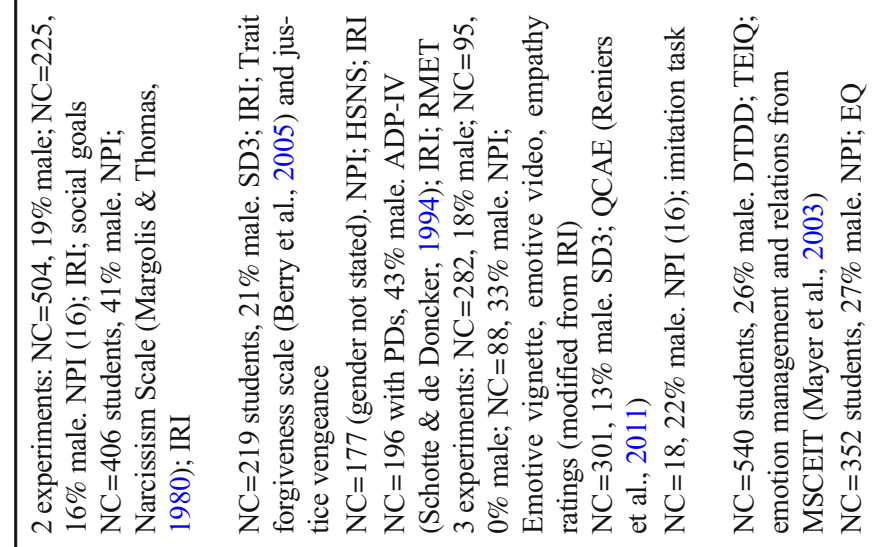

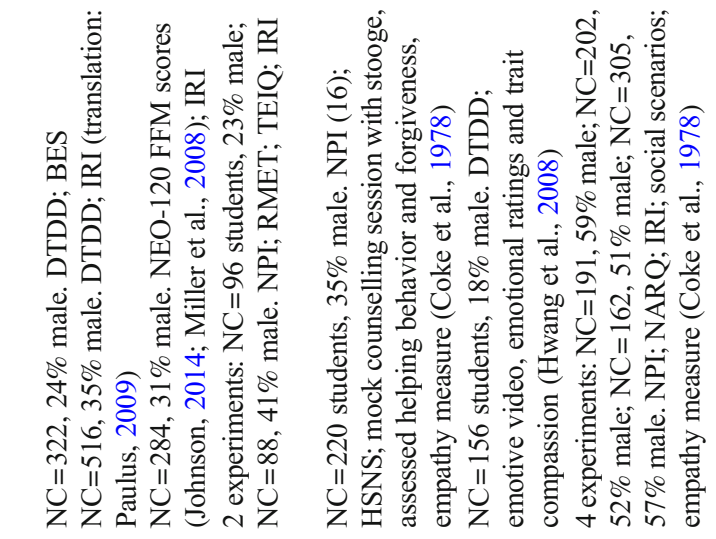

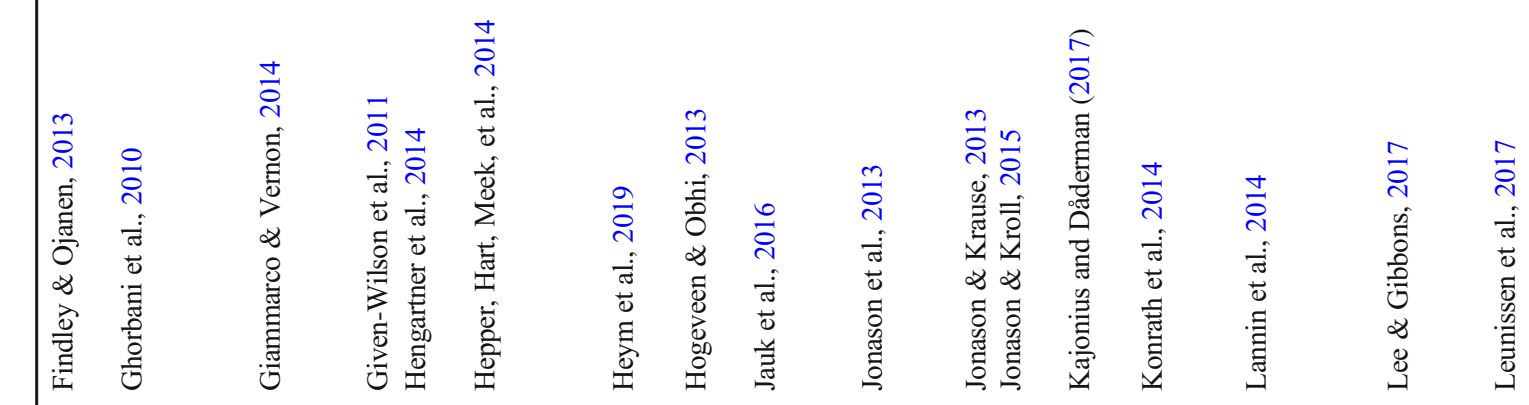

o 0
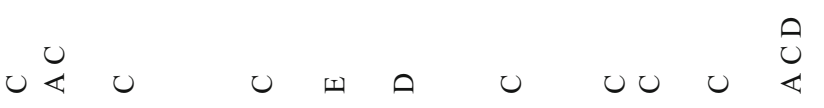


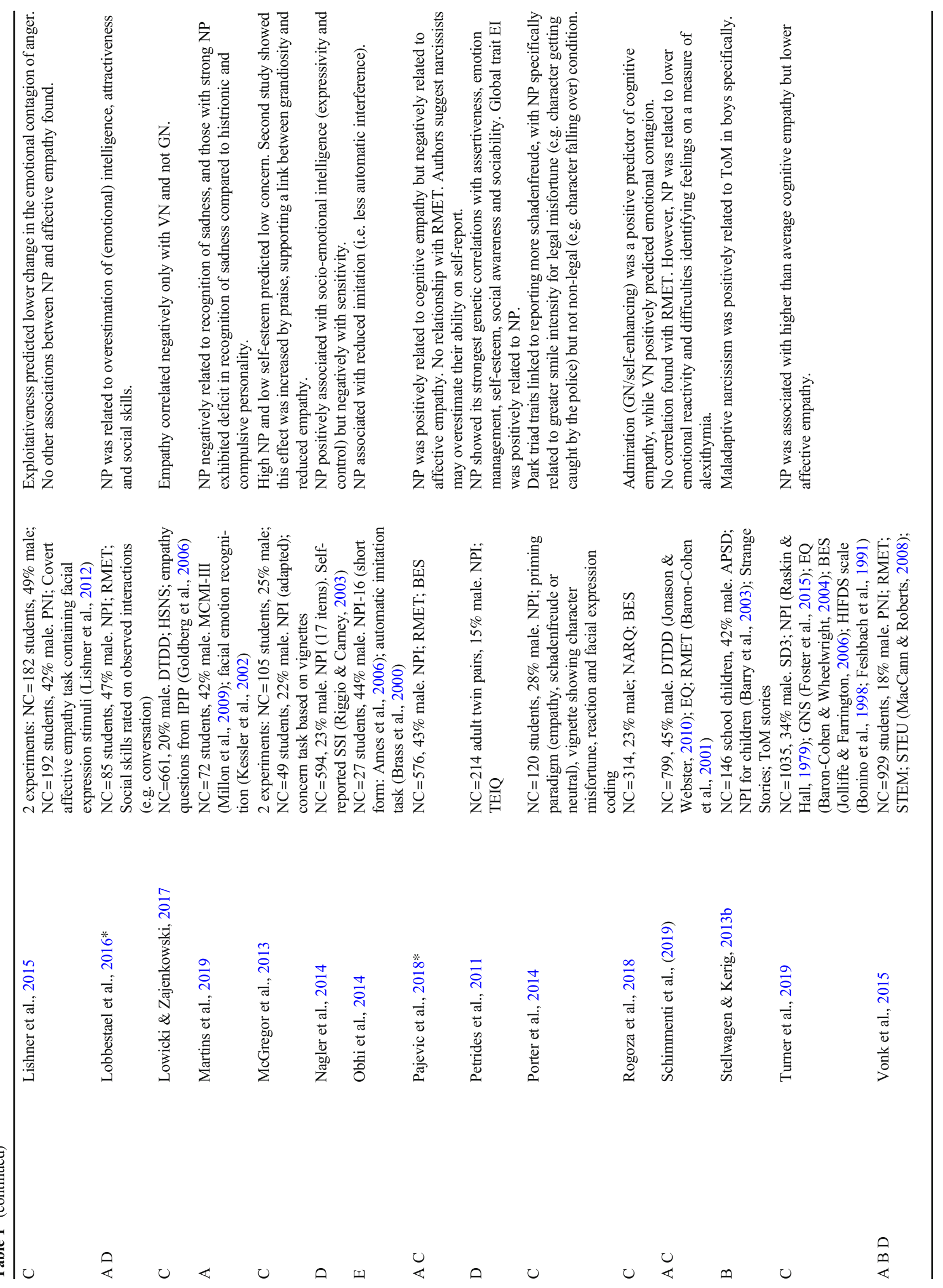




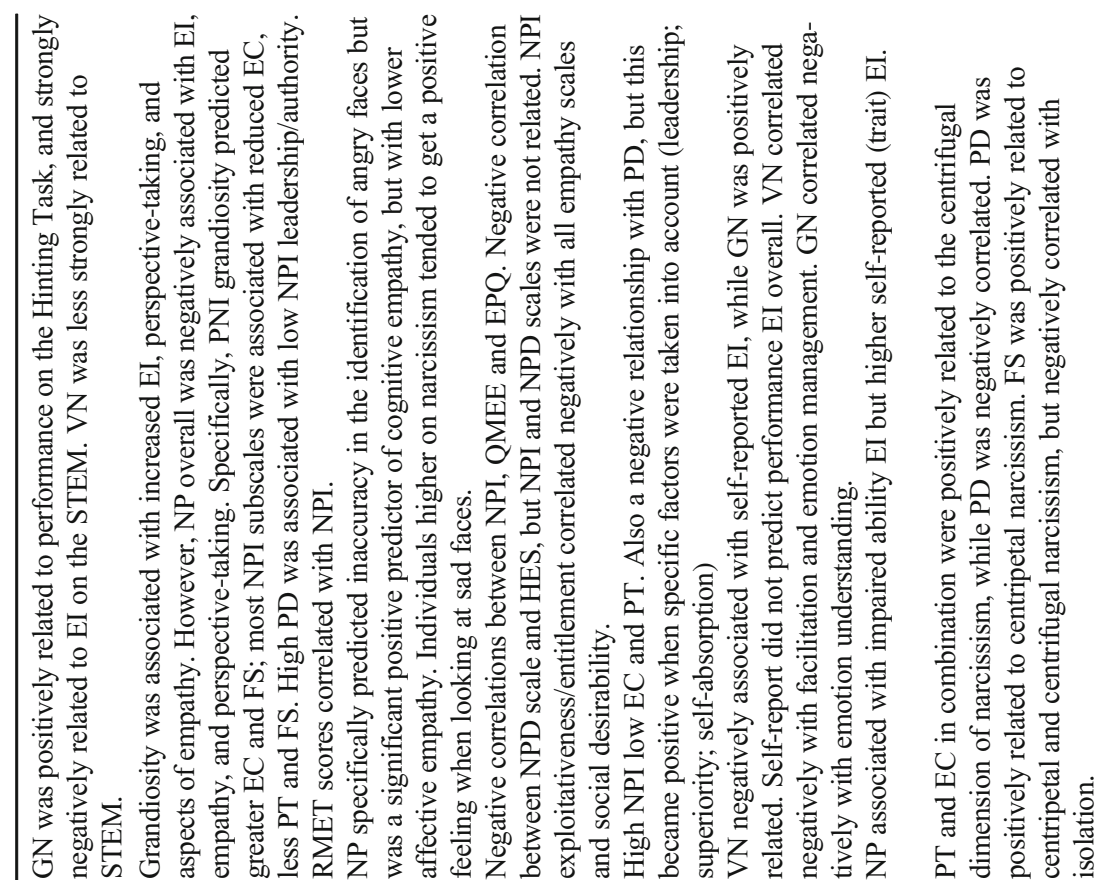

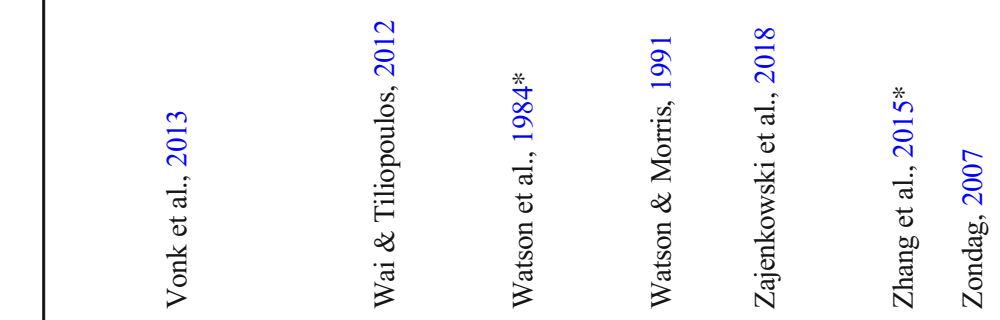

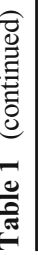

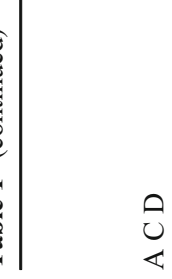

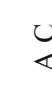

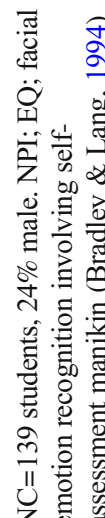

番

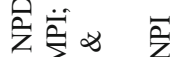

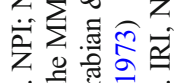

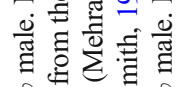
$\therefore$ 西题

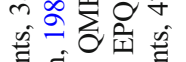

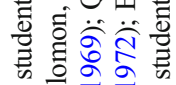
8 : II

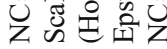

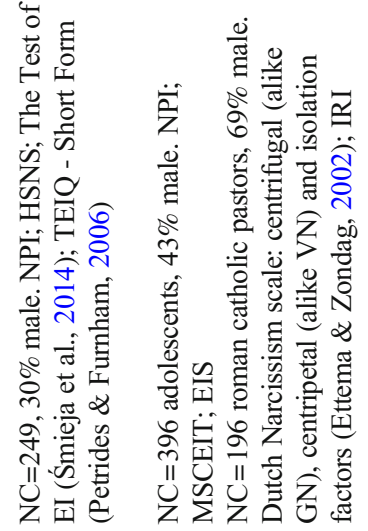

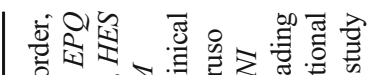

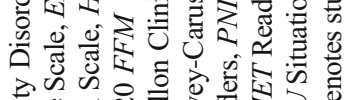

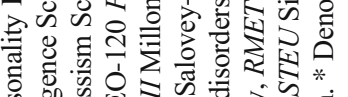

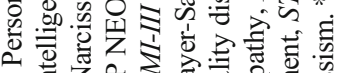

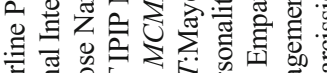
尊.

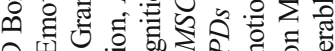

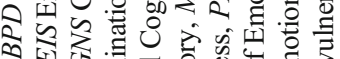

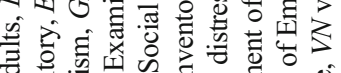

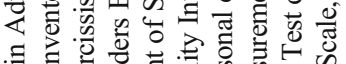

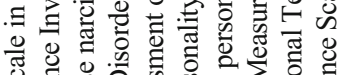

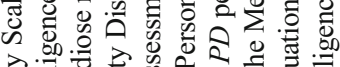

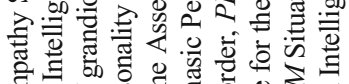

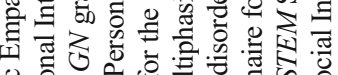

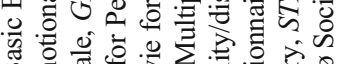

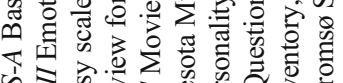

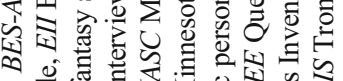

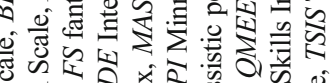

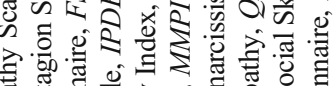

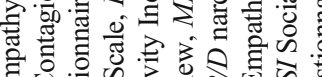

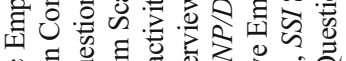

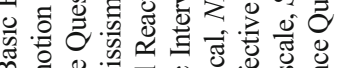

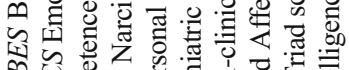

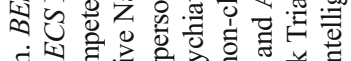

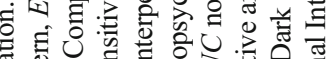

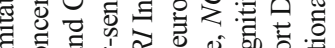

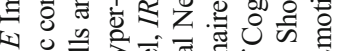
\&

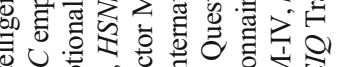

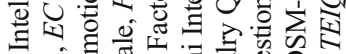

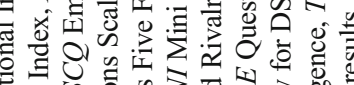

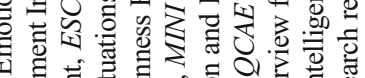

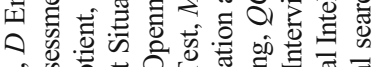

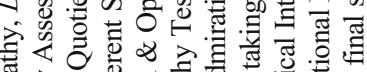

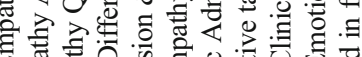

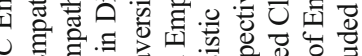

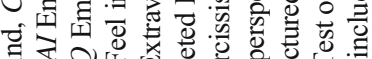

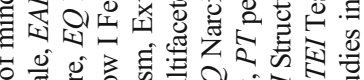

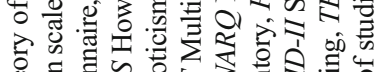

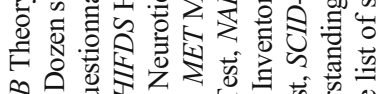

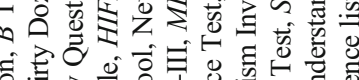

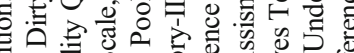

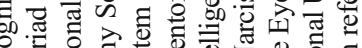

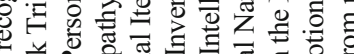

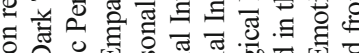
응. 可

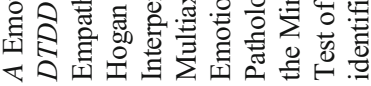


which is a forced choice task requiring participants to select the complex mental state that best matches photographs of human eyes. While some authors refer to the RMET as a test of ToM, its creators (Baron-Cohen et al., 2001) did distinguish between two stages of ToM: one involving mental state decoding (i.e. recognition) and another involving higher level reasoning. Consensus is now building that the RMET is perhaps more precisely a test of emotion or mental state recognition (Oakley et al., 2016). Indeed, performance on the RMET is more closely associated with performance on emotion perception tasks than ToM tasks (Kittel et al., 2021). This is probably because the RMET involves interpreting only what is contained within the visual stimulus (i.e. the image of the eyes) rather than any kind of situational or social context, and so requires less abstract reasoning of the kind involved in typical ToM tasks (Eddy, 2019). Very few of the reviewed studies included standard measures of ToM such as story vignettes (i.e. assessing more abstract reasoning about mental states, including beliefs or intentions). Indeed, some tasks used very frequently in the wider clinical literature were notably absent (e.g. the Faux Pas Task; Stone et al. 1998). Finally, three studies included tasks assessing imitation of the perceived actions of others.

\section{Study Findings According to Social Cognitive Domain}

\section{Empathy}

Six studies used the IRI in a clinical/forensic or targeted population, three of which omitted the FS subscale and two of which omitted the PD subscale. One study using between group comparisons found no difference on the included PT and EC subscales between participants with NPD in comparison to controls (Marissen et al., 2012), two others did find a difference for PT but not for EC (Marcoux et al., 2014; Ritter et al., 2011) with one of these including the PD subscale and also finding no difference for this (Marcoux et al., 2014). In a sample of emotionally abusive parents, Wiehe (2003) found evidence of a negative relationship between exhibitionism and entitlement and both PT and EC in abusive parents, while Romero-Martínez et al. (2016) reported no relationship between narcissism and IRI scores in perpetrators of interpersonal violence. Finally, a study in a forensic population with subclinical narcissistic traits found negative correlations between these traits and both PT and EC (Hepper, Hart, \& Sedikides, 2014). Therefore reduced PT seems to be a likely finding in groups with pathological narcissism, although data relating to the other IRI cognitive empathy subscale (i.e. fantasy) is lacking.

Sixteen other studies investigated empathy using the IRI, in non-clinical samples. One included just the EC subscale and didn't report a direct correlation with the measure of narcissism (Konrath et al., 2014). Of the remaining 15 studies, 14 included the PT subscale. Seven reported no relationship with NP. However, of the seven that did, six found a negative association. Therefore, while an association may be present only half of the time in non-clinical populations (perhaps due to sample variations in the severity of narcissistic traits), the pattern is reduced self-reported cognitive empathy in those individuals showing more narcissism, perhaps especially in association with prominent exploitativeness/entitlement traits. Twelve of the 15 studies included the fantasy subscale. Six reported no correlation, four studies reported a positive association and two a negative association. Of those reporting a positive correlation with NP, Given-Wilson et al. (2011) found this to be specific to the HSNS, while a negative correlation was reported only in relation to the PNI and not the NPI in the study by Vonk et al. (2013). Fantasy related perspective taking (e.g. imagining oneself as a lead character in a film) could therefore be increased in at least some people with NP. However, results across studies are very mixed, and could be influenced by the presence of VN or sensitivity of NP scale used. The EC subscale of the IRI was used in all 15 studies as a measure of affective empathy, with 9 reporting a tendency for individuals with high NP scores to self-report reduced affective empathy compared to with low NP scores, and one more a trend towards this effect. Just one study (Zondag, 2007) reported a positive relationship between EC and narcissism using a Dutch rating scale. The picture in relation to PD appears less clear, as while this subscale was used by 13 of the 15 studies, three studies reported a negative correlation with $\mathrm{NP}$, four reported a positive correlation, and 6 no effect. One interesting study (Zondag, 2007) found a positive correlation with traits more closely linked to $\mathrm{VN}$, and a negative relationship with traits more likely to be associated with GN.

In relation to the other empathy scales, where effects were found, they tended to fit the overall pattern of no self-reported loss of cognitive empathy, but evidence for diminished affective empathy. For example, NP can be associated with lower EQ scores (e.g. Jonason et al., 2013), and perhaps higher scores for cognitive perspective taking on the Questionnaire of Cognitive and Affective Empathy (Reniers et al., 2011) but reduced emotional empathy according to this same scale (Heym et al., 2019). In relation to associations with specific narcissistic traits or subtypes, studies using the NARQ have suggested that those with prominent traits related to admiration seek less revenge and show greater behavioral empathy in contrast to those with stronger rivalry (who seek more revenge and lack behavioral empathy; see Fatfouta Gerlach, Schroeder-Abe, Merkl and 2015; also Burgmer et al., 2019). Importantly, NARQ admiration may correspond best with GN while rivalry may be more prominent in those with lower selfesteem who tend towards VN (Back et al., 2013; Miller, Gentile and Campbell, 2013; Rogoza et al., 2018). Finally, it has also been suggested that BPD type traits could impact presentation (Ritter et al., 2011). 
Direct comparisons between self-report and behavioral measures of empathy were rare, despite being helpful in determining whether deficits related to motivation or competence (Hepper, Hart, Meek, et al., 2014; Kojonius \& Bjorkman, 2020). Existing studies hint at the possibility that motivation could depend on the aspect of social cognition in question. For example, high NP scores can be associated with self-report of increased emotional contagion when more objective evidence doesn't support this (Czarna et al., 2015), perhaps suggesting a social desirability effect. On the other hand, another study found that self-reports of low cognitive empathy (PT scores) were related to objective behaviour (punishment exhibited towards another person) during a different study task (Böckler et al., 2017).

\section{Emotional Intelligence}

Emotional intelligence was assessed in 14 of the 62 studies identified from the search, generally with self-assessment scales. Just one study (Weise \& Tuber, 2004) looked at emotional intelligence in a small sample of children with NPD, reporting lower scores for emotional investment in values but higher scores for investment in relationships, perhaps suggesting a difference in the number rather than quality of social contacts in children with NPD. Of the 13 studies in nonclinical groups, a couple reported no association (e.g. Czarna et al., 2016; Konrath et al., 2014), while the other studies uncovered quite specific relationships (Table 1). For example, Nagler et al. (2014) found narcissism was positively related to expressivity and control but negatively related to sensitivity to others' emotions. A couple of studies report a positive correlation between the NPI and TEIQ (Austin et al., 2014; Petrides et al., 2011) versus a negative relationship between the HSNS and TEIQ (Austin et al., 2014). This latter finding could reflect a weakness in VN specifically, a suggestion that is supported by lower self-ratings of emotional intelligence in association with VN when using other measures (Casale et al., 2019; Zajenkowski et al., 2018). However, the authors are careful to note such self-ratings may not predict actual performance. Other studies highlight a similar point, but have found that ability can be low when trait emotional intelligence can be self-reported as high (Jauk et al., 2016; Zhang et al., 2015), such that narcissism is more often associated with over-rating ability (Ames \& Kammrath, 2004; Lobbestael et al., 2016). These studies tended to use the NPI (although Jauk et al. used the DTDD) perhaps indicating that this pattern may be more closely related to GN.

\section{Emotion Recognition}

Thirteen of the 62 studies explored emotion recognition from visual (more rarely also including aural) stimuli in NP, and one additional study included emotional facial expressions as stimuli (Lishner et al., 2015) although the task itself was better described as a measure of empathy and explicit recognition of the expressions was not tested. In one study, participants with NPD showed a deficit in recognising fear and disgust (Marissen et al., 2012) and another found that narcissism predicted $2.5 \%$ amount of variance in RMET scores within perpetrators of interpersonal violence (Romero-Martínez et al., 2016). Of the 11 remaining studies in non-clinical samples, 6 studies reported no effect. However, NP has been found to be negatively related to recognition of sadness (Martins et al., 2019), and anger (Wai \& Tiliopoulos, 2012), and a couple of studies have found correlations between the NPI and RMET (Konrath et al., 2014; Vonk et al., 2013), so findings may depend on the prominence of certain NP traits. There is also evidence that NP can influence estimations of performance on the RMET (Lobbestael et al., 2016), encouraging further investigation into the relationships between metacognition, motivation, confidence and task performance in association with narcissism. Interestingly, De Panfilis et al. (2019) found that participants with higher NP scores were faster than those with low scores at accurately recognizing neutral and low intensity emotional facial expressions. This could suggest hypervigilance toward subtle negative emotions and neutral expressions, and was a pattern of performance found to be associated with sensitivity to rejection. In this study, NP was also related to greater fantasy and PD (but lower PT and EC). This study raises the possibility of associations between potential strengths in the detection of emotion from facial expressions in association with an empathy profile and NP traits that may better characterise $\mathrm{VN}$.

\section{Theory of Mind}

While numerous previous studies may have included the RMET (discussed previously under the emotion recognition section) when aiming to measure ToM, studies assessing the more abstract and higher level reasoning aspects of social cognition remain scarce, numbering just 6 of the 62 studies reviewed. Two of these didn't use standard tasks but reported differences in mentalizing or empathy based on reflective discussion about personal experiences (Bilotta et al., 2018; Diamond et al., 2014) in samples with personality disorders including NPD. Another study in a NPD sample used the Movie for the Assessment of Social Cognition (Dziobek et al., 2006) and revealed low performance on the cognitive empathy score, but this could have been influenced by comorbid BPD traits (Ritter et al., 2011). A couple of studies in children revealed interactions between NP and ToM ability, such that if both are high, maladaptive narcissistic traits and ringleader bullying were more likely (Stellwagen \& Kerig, 2013a\&b). Just one study was in a non-clinical sample, and this found that GN was related to good understanding of hints or indirect requests (cognitive ToM), but both GN and VN 
may be associated with weaknesses in understanding story character emotions (Vonk et al., 2015). In relation to the proposed difference between cognitive ToM and affective ToM (reasoning about beliefs and intentions versus reasoning about emotions, e.g. Shamay-Tsoory \& Aharon-Peretz, 2007), most studies focused on cognitive ToM, leaving the understanding of complex emotional states in others through abstract reasoning (e.g. verbal scenarios) a new avenue for exploration.

\section{Imitation}

Three studies explored narcissistic traits in non-clinical samples in relation to motor imitation tasks and these have been included based on the link between automatic imitation processes and understanding of emotions or intentions in others (i.e. simulation theory or the Mirror Neuron System; see Bastiaansen et al., 2009). These studies reported somewhat contradictory findings despite using very similar tasks (NPI and imitation task based on compatible and incompatible finger movements). Two studies (Hogeveen \& Obhi, 2013; Obhi, Hogeveen et al., 2014) reported reduced imitation interference in association with narcissism, and in turn the possibility of reduced motor resonance, which would perhaps be in line with diminished emotional empathy (if reduced resonance generalises to facial expressions). However, no such relationship was found by Butler et al. (2015).

\section{Study Findings According to NP Measures and Sample Characteristics}

\section{Measures of Narcissism}

Of the 62 studies included, 8 of the clinical studies did not include specific measures of NP, and only 18 studies included measures that were thought to cover aspects of VN (such as the PNI, HSNS, DTDD). These latter studies were compared to the 36 studies using measures which tended to focus more on GN (e.g. NPI, NARQ). Grandiosity was associated with higher ratings of EI and empathy (Vonk et al., 2013) and better emotion management (Vonk et al., 2015). Admiration was also positively related to empathy (Fatfouta et al., 2015; Lishner et al., 2015; Rogoza et al., 2018). However, empathy was negatively related to rivalry (Burgmer et al., 2019; Fatfouta et al., 2015; Rogoza et a;. 2018, Porter et al., 2014), exploitativeness (Hepper, Hart, Meek, et al., 2014), and fantasies of unlimited success and envy in a clinical sample (Bilotta et al., 2018). Those studies including measures of $\mathrm{VN}$ found that participants scoring highly were less confident about their social cognitive skills, rating empathy and emotional intelligence lower (Austin et al., 2014; Casale et al., 2019; Lannin et al., 2014; Lowicki \& Zajenkowski, 2017; Zajenkowski et al. 2018) despite appearing more emotionally reactive (De Panfilis et al., 2019; Jonason \& Kroll, 2015;
Rogoza et al., 2018; Wiehe, 2003; Zondag, 2007). In addition to PD, fantasy scores were also higher in VN when this scale was included (Given-Wilson et al., 2011; Jonason \& Kroll, 2015). Empathy could therefore be influenced by emotional states in NP, and fluctuating predominance of GN versus VN traits may underlie performance differences across studies.

\section{Sample Population}

Studies involving student samples (23/62) were compared to those involving a wider sample from the general population $(29 / 62)$, excluding the clinical studies (10/62). It was found that fewer of the student studies included scales that would measure traits more closely linked to $\mathrm{VN}$ (5 versus 14$)$, but that a similar amount of studies ( $\sim 33 \%)$ involving student and non-student samples included a fair proportion of males. Those that did explore VN in student populations reported evidence of lower self-reported empathy and emotional intelligence in comparison to GN, there was even greater evidence in the broader population, and also suggestions that $\mathrm{VN}$ could be associated with PD and greater emotion contagion (Rogoza et al., 2018; Zondag, 2007). Student studies reported more evidence of deficits in emotion recognition from facial expressions (e.g. Konrath et al., 2014; Martins et al., 2019; Wai \& Tiliopoulos, 2012) whereas there were no such deficits reported in 4 studies from the broader population (Fan et al., 2010; Hengartner et al., 2014; Pajevic et al., 2018) and possibly enhanced recognition of subtle expressions (De Panfilis et al., 2019).

\section{Gender}

Very few studies (6/62) achieved a sample of at least $50 \%$ males, so it was decided to compare studies including at least $40 \%$ males ( $n=26 / 62)$ to those including fewer than this ( $n=$ $34 / 62$; gender not reported by 2 studies). It was found that studies more balanced in relation to gender were less likely to focus on GN and more likely to involve clinical or forensic populations than those including many more females. Studies including at least $40 \%$ males were also less likely to report deficits in emotion recognition, apart from one clinical study (Marissen et al., 2012); and there was more evidence overall of low empathy and emotional intelligence in the more gender balanced studies, especially in the clinical studies. The pattern of findings for studies involving many more females tended to be more mixed, especially in relation to VN. Individual studies raised potential interactions between gender, co-morbidities, predominant NP traits and social cognition. For example, males are more likely to exhibit NPD in association with BPD (Ritter et al., 2011); males exhibit more psychopathic traits (Jauk et al., 2016); they are also more likely to exhibit GN (66\%; versus $33 \%$ of those with VN: Casale et al., 2019); exhibit lower empathy ratings (Jonason \& Kroll, 2015) and 
poorer emotion recognition (Martins et al., 2019) than females. Males can also be more emotionally manipulative than females (Casale et al., 2019) and may show different relationships between ToM ability and interpersonal behaviours such as bullying (Stellwagen \& Kerig, 2013a). Future research should therefore take into account the potential interactions between NP, gender and social cognition.

\section{Subjective Versus Objective Measures}

Of the 39 studies that included more objective measures (e.g. traditional lab tasks; emotionally evocative scenarios or images etc.), 13 included a visual emotion recognition task (e.g. RMET), just 4 explored ToM, 3 included imitation tasks (plus one study a pain resonance measure), 9 assessed emotional intelligence and 15 included empathy measures (a few studies contained more than objective measure). For the emotion recognition studies, effects were more likely to be noted in clinical samples and less likely in association with GN. Interestingly, a couple of studies have reported enhanced skills in association with NP (e.g. De Panfilis et al., 2019; Konrath et al., 2014) so future research should explore the possibility of varied performance according to the prominence of particular narcissistic traits. Imitation studies in younger non clinical samples found some evidence for reduced resonance in association with GN. However, one study suggested that NPD could be associated with increased resonance in association with pain observation (Marcoux et al., 2014). Most studies including a more objective measure of EI reported an association between NP and poorer performance, with one study suggesting a stronger effect in males (Jauk et al., 2016). Finally, the vast majority of studies using more objective empathy measures suggest that NP is associated with reduced empathy, particularly in situations associated with low self esteem, rivalry, guilt and punishment, even where measures more closely related to GN, such as the NPI, are used (e.g. Czarna et al., 2015; Hepper, Hart, Meek, et al., 2014; Leunissen et al., 2017; McGregor et al., 2013; Porter et al., 2014).

\section{Discussion}

A review of social cognition in narcissism identifies highly variable findings, a bias towards the investigation of empathy (and sometimes emotional intelligence) through the use of self-report scales, and utilisation of a range of measures of NP. Nevertheless, there is an emerging consensus in relation to the empathy profile of narcissism, given that significant NP traits typically predict reduced IRI PT scores in both clinical and subclinical populations, including in a recent metaanalysis (Urbonaviciute \& Hepper, 2020). Social cognitive profile may also vary according to predominant narcissistic traits or subtype. Furthermore, it can be questioned whether perspective taking in general is reduced, given findings of increased IRI fantasy subscale scores. This would make sense given the potential for fantasies about success and reference to grandiose fantasy in some NP scale items (e.g. Pincus et al., 2009). However, at least one study has found an association between higher FS and VN (Given-Wilson et al., 2011). Perhaps the fantasy subscale can pick up on narcissistic proneness to imagine oneself in self-enhancing or desirable roles (e.g. the hero or seductress), while taking on the more mundane perspectives of ordinary people (as assessed by the PT subscale) is less appealing.

The EC subscale score is also frequently low in samples with narcissism, although this may be most likely when VN traits are apparent. It is interesting to note that low empathic concern may not typically be considered socially desirable. However, it could be that narcissists consider high emotional empathy to be a sign of weakness or vulnerability, perhaps due to a focus more on its personal disadvantages (see BaskinSommers et al., 2014). Mixed findings in relation to PD may reflect the type of dominant narcissistic traits e.g. higher $\mathrm{PD}$ is more likely in association with VN (Rogoza et al., 2018), and $\mathrm{VN}$ in turn is linked to less emotional stability than GN. Broader research in psychiatry has reported elevated PD in patients with other psychiatric disorders such as schizophrenia, and such tendencies could contribute to numerous problematic social behaviors (Eddy, 2018). Exploring the potential differences between PD in VN and GN may reveal different bases for behaviors that apparently demonstrate a lack of empathy, perhaps with VN being more reflective of avoidance or a self-protective strategy rather than the interpersonal insensitivity or indifference one may associate with GN.

The findings across studies assessing emotional intelligence, emotion recognition and ToM are very mixed. Emotional intelligence, like PT and EC, can be lower as rated by individuals with NP, but perhaps especially by those with high VN traits. On the contrary, GN may lead to reports of higher ability. Few studies included concurrent objective measures of emotional intelligence or social cognition in addition to self-report scales, but those which did reported more evidence of deficits in clinical samples and those of balanced gender. In relation to emotion recognition, although replication is needed, reports of impairments in the recognition of negative facial expressions are perhaps surprising given the high functioning of many individuals with significant narcissistic traits. As highlighted by De Panfilis et al. (2019) studies should be careful to use measures which can identify subtle performance differences on these types of tasks, such as reaction times. Few conclusions can be drawn about ToM, given that studies assessing this form of social reasoning are scarce overall, surprisingly so in relation to subclinical narcissism. In particular there is also a lack of studies assessing mentalising about emotions on standard 
ToM tasks. A similar pattern could emerge to that found for empathy such that narcissism may typically feature a conscious focus on abstract reasoning about cognitive mental states, with reduced propensity towards attempting to reason about emotional states. Such tendencies could also help to explain the narcissistic romantic love style which apparently seeks to control the partner's mind, rather than their heart (Jonason \& Kavanagh, 2010).

Some studies highlight relationships between reduced empathy and specific narcissistic features such as grandiosity (Vonk et al., 2013), exploitativeness (Hepper, Hart, Meek, et al., 2014; Watson et al., 1984) and rivalry (Burgmer et al., 2019; Fatfouta et al., 2015). While exploitation may be at the core of NP (Miller et al., 2016), a lack of empathy may also help to explain a lack of forgiveness, which may be more frequently associated with VN (Fatfouta et al., 2015; Konrath et al., 2014). Furthermore, it has been suggested that empathic functioning may vary according to narcissistic subtype, such that in GN it is driven by egocentric motivation-based attachment security, but in $\mathrm{VN}$ it may reflect emotional and attachment instability (Baskin-Sommers et al., 2014). If this is the case, one may expect selective application of social cognition in GN (e.g. in accordance with ego need), while difficulties in controlling 'ego-dystonic' mentalising could help to explain the social withdrawal and victim mentality seen in VN (McCullough et al., 2003). Overall, those with VN appear less confident about their social cognitive abilities, and may be more easily influenced by the emotional states of others. Indeed, the current findings support the utility of comparisons between GN and VN, but also highlight the importance of considering individual characteristics such as rivalry and admiration. It is possible that some relationships picked up by studies could reflect state rather than trait effects (e.g. rivalry or envy could interact with mood state as well as social cognition).

Grandiosity in particular, has been suggested to predict strengths in social cognition (Vonk et al., 2013), whereas high leadership/authority traits are linked to weaknesses (although this latter effect could be advantageous when empathy limits personal gain). Those with GN rate themselves as more empathic, but where performance is not in accordance with this, it could imply a lack of insight. Alternatively, discrepancies between self-report and behaviour could reflect the application of self regulatory strategies, such as interpersonal detachment and emotional inhibition (Horvath \& Morf, 2009; Pincus et al., 2009; Ronningstam, 2005). In other words, those with narcissism perhaps possess the necessary social cognitive skills, but are simply more judicious in their application. Numerous behaviors associated with narcissism imply selfserving employment of mental state understanding. For example, while exploitativeness may imply a lack of empathy, it requires strengths in cognitive ToM in order to understand best how to manipulate another person's beliefs or intentions (Konrath et al., 2014). Indeed, narcissists can show a good understanding of cognitive ToM, given that they can understand hints and indirect requests (Vonk et al., 2015). A successful narcissist may selectively apply cognitive ToM to help maintain other's beliefs about oneself to sustain grandiose notions, while avoiding emotional ToM in order to ignore other's negative emotions and in turn, reduce feelings of personal guilt (Nagler et al., 2014). Such strategies could be psychologically beneficial. For example, one recent study highlighted increased mental resilience (Papageorgiou et al., 2019) in those with subclinical GN, and a lower incidence of depression. However, individuals with VN exhibited less mental toughness and greater stress. Exploring the relationship between mental resilience and social cognitive strategies in narcissism could uncover the potential reinforcement value of problematic interpersonal behaviors. Another potential avenue of exploration is that of the influence of gender, especially given that GN may be more closely linked to the male gender, while VN shows no gender difference (Grijalva et al., 2015). Mixed findings across studies could partly reflect interactions between gender and both predominant narcissistic traits and sex related difference on social cognitive tasks (e.g. Baron-Cohen \& Wheelwright, 2004; Brackett \& Salovey, 2006; McClure, 2000).

Ironically, potential strengths in social cognition can at times be problematic to an individual (e.g. where skills are applied excessively). In the case of NPD, some characteristics such as excessive jealousy and paranoia (Day et al., 2020), could arise in association with over-mentalizing, rather than a reduction in social reasoning. Envy may result from the comparison between one's own and another person's mental state. (e.g. I am not satisfied whereas you are satisfied), and suspiciousness of others may result through the attribution of hostile intent (e.g. you are motivated to take advantage of me). Such features can occur more frequently in VN and have the potential to lead to hostile behaviors (Miller et al., 2018). The possibility of hyper-mentalizing appears unexplored in narcissism and work in this area could prove insightful.

Another interesting aspect of NP that encourages further assessment of social cognition is frequent use of deception. Those with prominent narcissistic traits often demonstrate a propensity for lying and believe they are good at deceiving others (Elaad \& Zvi, 2019; Giammarco et al., 2013; Oliveira \& Levine, 2008). Lying may be dependent on the ability to fantasize, but good liars are likely to need a good understanding of the cognitive mental states of the person they are lying to (e.g. that persons beliefs and expectations), and low empathy in order to feel comfortable with deceiving another hence not giving away non-verbal signals which could lead to detection. This pattern is largely in accordance with the findings of this review. However, a preference for absorption in selfenhancing counterfactual realities and high frequency of lying emphasize the need to interpret self-report measures with caution when working with this population. Further limitations and pointers for future research are given in Table 2. 
Table 2 Limitations and recommendations for future research

Limitations

- Few studies were available in pathological narcissism

- High number of studies involving student samples and mainly females

- Some studies didn’t consider subtypes such as GN and VN.

- Our conceptualization of narcissistic personality continues to develop.

- The NPI (used by the majority of studies) focuses more on the grandiose and confident aspects of NP than the distressed aspects ${ }^{\mathrm{a}}$

- Limited application of standard social cognitive tasks assessing ToM and emotion recognition.

- Frequent reliance on self-report measures without concurrent assessment of performance

- Poor control for confounds (attention, motivation, mood etc.) sometimes including co-morbidities (e.g. Borderline Personality Disorder)

- Variation in measures used and unknown psychometric characteristics of some measures

- Interpreting correlations in terms of causation

- Assessment of traits but little insight into relationships with everyday behaviors
Recommendations for future research

- Follow up and replicate early findings in emotion recognition and ToM

- Evaluate the influence of factors such as emotional valence, emotional state and egocentricity (e.g. priming studies)

- Explore relationships between social cognition and measures relating to the self, as well as specific narcissistic traits and behaviours

- Consider possible influences of gender and mood

- Concurrently assess insight and self-reflection

- Include subtle measures such as reaction times, confidence ratings etc.

- Improve ecological validity by measuring spontaneous mentalizing or using more covert measures of social cognition

- Include control measures e.g. taking another person's perspective versus imagining the self from an alternative perspective

- Consider the influence of factors such as memory and perception (especially in NPD)

- Investigate whether the adoption of maladaptive social cognitive strategies during development give rise to NP traits or vice versa (e.g. developmental/ longitudinal studies)

- Use a range of concurrent tasks in order to compare skills such as mirroring (e.g. emotion contagion) and mentalizing, and explore the potential role of self-other differentiation

- Consider the multidimensional nature of the GN admiration and rivalry concept $\mathrm{t}^{\mathrm{b}}$ now thought to consist of neurotic, agentic and antagonistic factors $^{\mathrm{c}}$

-Where possible, meta-analyses of specific social cognitive tasks may help evaluate the available evidence

${ }^{\mathrm{a}}$ Miller and Campbell (2008); ${ }^{\mathrm{b}}$ Back et al. (2013); ${ }^{\mathrm{c}}$ Crowe et al. (2019); ${ }^{\mathrm{d}}$ Grove et al. (2019)

\section{Conclusion}

Patterns of social interaction could be said to define the narcissist, who applies social-cognitive affective intrapersonal and interpersonal self-regulatory strategies in order to construct and maintain their excessively favourable self-views (Campbell \& Foster, 2007; Morf \& Rhodewalt, 2001). An egocentric imbalance is frequently apparent, whereby the narcissistic individual demands attention, admiration and indulgence, and buffers self-esteem through feelings of power, superiority and specialness, often devaluing or dismissing the desires and abilities of others. Given that such behaviors are likely to deliver intrinsic reinforcement, how are they to be corrected in pathological cases? Directly attempting to increase affective empathy would seem unlikely to be successful unless underlying difficulties with the narcissists own self-serving perceptions, or vulnerabilities in self-esteem (e.g. Zeigler-Hill et al., 2010; Zeigler-Hill \& Besser, 2013) are also addressed. Moreover, interventions to enhance social cognitive skills may not actually be necessary, given that the NPD may simply involve a developmentally acquired pattern of self-serving social cognitive strategy use. Whatever the case, social cognition is intricately interwoven into the fabric of narcissistic personality, and understanding more about how strong narcissistic traits provoke specific responses to the thoughts, intentions and emotions of self and other will make an invaluable contribution to any therapeutic process.
Supplementary Information The online version contains supplementary material available at https://doi.org/10.1007/s12144-021-01661-3.

Code Availability Not applicable.

Authors' Contributions This review was the work of a single author.

Funding This research was unfunded.

Data Availability Data sharing not applicable to this article as no datasets were generated or analysed during the current study.

\section{Declarations}

Conflict of Interest The author declares that they have no conflicts of interest.

Ethics Approval Not applicable.

Consent to Participate Not applicable.

Consent for Publication Not applicable.

Open Access This article is licensed under a Creative Commons Attribution 4.0 International License, which permits use, sharing, adaptation, distribution and reproduction in any medium or format, as long as you give appropriate credit to the original author(s) and the source, 
provide a link to the Creative Commons licence, and indicate if changes were made. The images or other third party material in this article are included in the article's Creative Commons licence, unless indicated otherwise in a credit line to the material. If material is not included in the article's Creative Commons licence and your intended use is not permitted by statutory regulation or exceeds the permitted use, you will need to obtain permission directly from the copyright holder. To view a copy of this licence, visit http://creativecommons.org/licenses/by/4.0/.

\section{References}

Ackerman, R. A., Witt, E. A., Donnellan, M. B., Trzesniewski, K. H., Robins, R. W., \& Kashy, D. A. (2011). What does the narcissistic personality inventory really measure? Assessment, 18(1), 67-87.

American Psychiatric Association. (2013). Diagnostic and statistical manual of mental disorders (4th ed.). Author.

Ames, D., \& Kammrath, L. (2004). Mind-reading and metacognition: Narcissism not actual competence, predicts self-estimated ability. Journal of Nonverbal Behavior, 28(3), 187-209.

Ames, D. R., Rose, P., \& Anderson, C. P. (2006). The NPI-16 as a short measure of narcissism. Journal of Research in Personality, 40, 440 450.

Austin, E. J., Saklofske, D. H., Smith, M., \& Tohver, G. (2014). Associations of the managing the emotions of others (MEOS) scale with personality, the dark triad and trait EI. Personality and Individual Differences, 65, 8-13.

Back, M. D., Küfner, A. C., Dufner, M., Gerlach, T. M., Rauthmann, J. F., \& Denissen, J. J. (2013). Narcissistic admiration and rivalry: Disentangling the bright and dark sides of narcissism. Journal of Personality and Social Psychology, 105(6), 1013-1037.

Back, M. D., Schmukle, S. C., \& Egloff, B. (2010). Why are narcissists so charming at first sight? Decoding the narcissism-popularity link at zero acquaintance. Journal of Personality and Social Psychology, 98(1), 132-145.

Bar-On, R. (1997). The emotional intelligence inventory (EQ-i): Technical manual. Multi-Health Systems.

Baron-Cohen, S., \& Wheelwright, S. (2004). The empathy quotient: An investigation of adults with Asperger syndrome or high functioning autism, and normal sex differences. Journal of Autism and Developmental Disorders, 34(2), 163-175.

Baron-Cohen, S., Wheelwright, S., Hill, J., Roste, Y., \& Plumb, I. (2001). The 'reading the mind in the eyes' test revised version: A study with normal adults, and adults with Asperger syndrome or high-functioning autism. Child Psychology and Psychiatry, 42(2), 241-251.

Barry, C. T., Frick, P. J., \& Killian, A. L. (2003). The relation of narcissism and self-esteem to conduct problems in children: a preliminary investigation. Journal of Clinical Child \& Adolescent Psychology, 32(1), 139-152.

Baskin-Sommers, A., Krusemark, E., \& Ronningstam, E. (2014). Empathy in narcissistic personality disorder: From clinical and empirical perspectives. Personality Disorders, 5(3), 323-333.

Bastiaansen, J. A., Thioux, M., \& Keysers, C. (2009). Evidence for mirror systems in emotions. Philosophical Transactions of the Royal Society of London B Biological Sciences, 364(1528), 2391-2404.

Batson, C. D., \& Shaw, L. L. (1991). Evidence for altruism: Toward a pluralism of prosocial motives. Psychological Inquiry, 2(2), 107-122.

Berry, J. W., Worthington Jr., E. L., O'Connor, L. E., Parrott III, L., \& Wade, N. G. (2005). Forgivingness, vengeful rumination, and affective traits. Journal of Personality, 73, 183-225.

Bilotta, E., Carcione, A., Fera, T., Moroni, F., Nicolò, G., Pedone, R., Pellecchia, G., Semerari, A., \& Colle, L. (2018). Symptom severity and mindreading in narcissistic personality disorder. PLoS One, 13(8), e0201216
Böckler, A., Sharifi, M., Kanske, P., Dziobek, I., \& Tania, S. (2017). Social decision making in narcissism: Reduced generosity and increased retaliation are driven by alterations in perspective-taking and anger. Personality and Individual Differences, 104, 1-7.

Bonino, S., Lo Coco, A., \& Tani, F. (1998). Empatia. Processi di condivisione delle emozioni. Giunti.

Bowers, D., Blonder, L. X., \& Heilman, K. M. (1989). The Florida affect battery, Revised. The Center for Neuropsychological Studies, University of Florida.

Brackett, M. A., \& Salovey, P. (2006). Measuring emotional intelligence with the Mayer-Salovery-Caruso emotional intelligence test (MSCEIT). Psicothema, 18(S), 34-41.

Bradley, M. M., \& Lang, P. J. (1994). Measuring emotion: The selfassessment manikin and the semantic differential. Journal of Behavior Therapy and Experimental Psychiatry, 25(1), 49-59.

Brass, M., Bekkering, H., Wohlschlager, A., \& Prinz, W. (2000). Compatibility between observed and executed finger movements: Comparing symbolic, spatial, and imitative cues. Brain and Cognition, 44(2), 124-143.

Brown, M. F. D., Stanton, K., \& Watson, D. (2020). Replicable factor structure and correlates of an alternate version of the narcissistic personality inventory. Journal of Psychopathology and Behavioral Assessment, 42(1), 69-85.

Burgmer, P., Weiss, A., \& Ohmann, K. (2019). I don’t feel ya: How narcissism shapes empathy. Self and Identity. Advance online publication, 20, 199-215. https://doi.org/10.1080/15298868.2019. 1645730

Butler, E. E., Ward, R., \& Ramsey, R. (2015). Investigating the relationship between stable personality characteristics and automatic imitation. PLoS One, 10(6), e0129651.

Caligor, E., Levy, K. N., \& Yeomans, F. E. (2015). Narcissistic personality disorder: Diagnostic and clinical challenges. American Journal of Psychiatry, 172(5), 415-422.

Campbell, W. K., \& Foster, J. D. (2007). The narcissistic self: Background, an extended agency model, and ongoing controversies. In C. Sedikides \& S. Spencer (Eds.), Frontiers in social psychology: The self (pp. 115-138). Psychology Press.

Carré, A., Stefaniak, N., D’Ambrosio, F., Bensalah, L., \& BescheRichard, C. (2013). The basic empathy scale in adults (BES-A): Factor structure of a revised form. Psychological Assessment, 25(3), 679-691.

Casale, S., Rugai, L., Giangrasso, B., \& Fioravanti, G. (2019). Traitemotional intelligence and the tendency to emotionally manipulate others among grandiose and vulnerable narcissists. The Journal of Psychology, 153(4), 402-413.

Coke, J. S., Batson, C. D., \& McDavis, K. (1978). Empathic mediation of helping: A two-stage model. Journal of Personality and Social Psychology, 36, 752-766.

Corcoran, R., Mercer, G., \& Frith, C. D. (1995). Schizophrenia, symptomatology and social influence: Investigating "theory of mind" in people with schizophrenia. Schizophrenia Research, 17, 5-13.

Costanzo, M., \& Archer, D. (1989). Interpreting the expressive behavior of others: The Interpersonal Perception Task. Journal of Nonverbal Behavior, 13(4), 225-245.

Costanzo, M., \& Archer, D. (1993). Interpersonal perception task-15 [videotape]. University of California Extension Center for Media and Independent Learning.

Crowe, M. L., Lynam, D. R., Campbell, W. K., \& Miller, J. D. (2019). Exploring the structure of narcissism: Toward an integrated solution. Journal of Personality, 87(6), 1151-1169.

Czarna, A. Z., Leifeld, P., Śmieja, M., Dufner, M., \& Salovey, P. (2016). Do narcissism and emotional intelligence win us friends? Modeling dynamics of peer popularity using inferential network analysis. Personality and Social Psychology Bulletin, 42, 1588-1599.

Czarna, A. Z., Wróbel, M., Dufner, M., \& Zeigler-Hill, V. (2015). Narcissism and emotional contagion: Do narcissists "catch" the 
emotions of others? Social Psychological and Personality Science, 6(3), 318-324.

Davis, M. H. (1983). Measuring individual differences in empathy: Evidence for a multidimensional approach. Journal of Personality and Social Psychology, 44(1), 113-126.

Day, N. J. S., Townsend, M. L., \& Grenyer, B. F. S. (2020). Living with pathological narcissism: A qualitative study. Borderline Personality Disorder and Emotion Dysregulation, 7, 19.

De Panfilis, C., Antonucci, C., Meehan, K. B., Cain, N. M., Soliani, A., Marchesi, C., Clarkin, J. F., \& Sambataro, F. (2019). Facial emotion recognition and social-cognitive correlates of narcissistic features. Journal of Personality Disorders, 33(4), 433-449.

Delič, L., Novak, P., Kovačič, J., \& Avsec, A. (2011). Self-reported emotional and social intelligence and empathy as distinctive predictors of narcissism. Psychological Topics, 20, 477-488.

Di Pierro, R., Di Sarno, M., Preti, E., Di Mattei, V. E., \& Madeddu, F. (2018). The role of identity instability in the relationship between narcissism and emotional empathy. Psychoanalytic Psychology, $35(2), 237-243$.

Diamond, D., Levy, K. N., Clarkin, J. F., Fischer-Kern, M., Cain, N. M., Doering, S., Hörz, S., \& Buchheim, A. (2014). Attachment and mentalization in female patients with comorbid narcissistic and borderline personality disorder. Journal of Personality Disorders, 5(4), 428-433.

Dinić, B. M., Petrović, B., \& Jonason, P. K. (2018). Serbian adaptations of the dark triad dirty dozen (DTDD) and short dark triad (SD3). Personality and Individual Differences, 134, 321-328.

Doherty, R. W. (1997). The emotional contagion scale: A measure of individual differences. Journal of Nonverbal Behavior, 21, 131-154.

Dziobek, I., Fleck, S., Kalbe, E., Rogers, K., Hassenstab, J., Brand, M., Kessler, J., Woike, J. K., Wolf, O. T., \& Convit, A. (2006). Introducing MASC: A movie for the assessment of social cognition. Journal of Autism and Developmental Disorders, 36, 623-636.

Eddy, C. M. (2018). Social cognition and self-other distinctions in neuropsychiatry: Insights from schizophrenia and Tourette syndrome. Progress in Neuropsychopharmacology and Biological Psychiatry, $82,69-85$.

Eddy, C. M. (2019). What do you have in mind? Measures to assess mental state reasoning in neuropsychiatric populations. Frontiers in Psychiatry, 10, 425.

Ekman, P., \& Friesen, W. (1976). Pictures of facial affect. Consulting Psychologist Press.

Elaad, E., \& Zvi, L. (2019). Frequent countermeasure usage by narcissistic examinees in the concealed information test. Frontiers in Psychology, 10, 1068.

Ettema, H., \& Zondag, H. (2002). De Nederlandse Narcisme Schaal (NNS). De Psycholoog, 37(5), 250-255.

Fan, Y., Wonneberger, C., Enzi, B., de Greck, M., Ulrich, C., Tempelmann, C., Bogerts, B., Doering, S., \& Northoff, G. (2010). The narcissistic self and its psychological and neural correlates: An exploratory fMRI study. Psychological Medicine, 41, 1641-1650.

Fatfouta, A., Gerlach, T. M., Schroeder-Abe, M., \& Merkl, A. (2015). Narcissism and lack of interpersonal forgiveness: The mediating role of state anger, state rumination, and state empathy. Personality and Individual Differences, 75, 36-40.

Feshbach, N. D., Caprara, G. V., Lo Coco, A., Pastorelli, C., Manna, G., \& Menzres, J. (1991). Empathy and its correlates: Cross cultural data from Italy. Eleventh biennal meeting of the International Society for the Study of Behavioral Development, Minneapolis.

Findley, D., \& Ojanen, T. (2013). Agentic and communal goals in early adulthood: Associations with narcissism, empathy, and perceptions of self and others. Self and Identity, 12(5), 504-526.

First, M. B., Spitzer, R. L., Gibbon, M., \& Williams, J. B. W. (1997). Structured clinical interview for DSM-IV personality disorders, (SCID-II). American Psychiatric Press.
Fonagy, P., Steele, M., Steele, H., \& Target, M. (1998). Reflective-function manual: Version 5.0 for application to the adult attachment interview. Unpublished manual, University College, London.

Foster, J. D., McCain, J. L., Hibbert, M., Brunell, A. B., \& Johnson, R. B. (2015). The grandiose narcissism scale: A global and facet-level measure of grandiose narcissism. Personality and Individual Differences, 73, 12-16.

Frick, P. J., \& Hare, R. D. (2001). The antisocial process screening device. Multi-Health Systems.

Fukushima, O., \& Hosoe, T. (2011). Narcissism, variability in self-concept, and well-being. Journal of Research in Personality, 45(6), 568-575.

George, C., Kaplan, N., \& Main, M. (1996). The Berkeley Adult Attachment Interview. Unpublished manuscript, Department of Psychology, University of California, Berkeley.

Ghorbani, N., Watson, P. J., Hamzavy, F., \& Weathington, B. L. (2010). Self-knowledge and narcissism in Iranians: Relationships with empathy and self-esteem. Current Psychology: A Journal for Diverse Perspectives on Diverse Psychological Issues, 29(2), 135-143.

Giammarco, E. A., Atkinson, B., Baughman, H. M., Veselka, L., \& Vernon, P. A. (2013). The relation between antisocial personality and the perceived ability to deceive. Personality and Individual Differences, 54, 246-250.

Giammarco, E. A., \& Vernon, P. A. (2014). Vengeance and the dark triad: The role of empathy and perspective taking in trait forgivingness. Personality and Individual Differences, 67, 23-29.

Given-Wilson, Z., McIlwain, D., \& Warburton, W. (2011). Metacognitive and interpersonal difficulties in overt and covert narcissism. Personality and Individual Differences, 50(7S1), 1000-1005.

Glover, N., Miller, J. D., Lynam, D. R., Crego, C., \& Widiger, T. A. (2012). The five-factor narcissism inventory: A five factor measure of narcissistic personality traits. Journal of Personality Assessment, $94,500-512$.

Goldberg, L. R., Johnson, J. A., Eber, H. W., Hogan, R., Ashton, M. C., Cloninger, C. R., \& Gough, H. C. (2006). The international personality item pool and the future of public-domain personality measures. Journal of Research in Personality, 40, 84-96.

Grijalva, E., Newman, D. A., Tay, L., Donnellan, M. B., Harms, P. D., Robins, R. W., \& Yan, T. (2015). Gender differences in narcissism: A meta-analytic review. Psychological Bulletin, 141(2), 261-310.

Grove, J. L., Smith, T. W., Girard, J. M., \& Wright, A. G. (2019). Narcissistic admiration and rivalry: An interpersonal approach to construct validation. Journal of Personality Disorders, 33(6), $751 \mathrm{v} 775$.

Gunderson, J., \& Ronningstam, E. (2001). Differentiating antisocial and narcissistic personality disorder. Journal of Personality Disorders, $15,103-109$

Happé, F. G. E. (1994). An advanced test of theory of mind: Understanding of story characters' thoughts and feelings by able autistic, mentally handicapped, and normal children and adults. Journal of Autism and Developmental Disorders, 24(2), 129-154.

Hendin, H. M., \& Cheek, J. M. (1997). Assessing hypersensitive narcissism: A re-examination of Murray's Narcism scale. Journal of Research in Personality, 31(4), 588-599.

Hengartner, M. P., Ajdacic-Gross, V., Rodgers, S., Müller, M., Haker, H., \& Rössler, W. (2014). Fluid intelligence and empathy in association with personality disorder trait-scores: Exploring the link. European Archives of Psychiatry and Clinical Neuroscience, 264(5), 441-448.

Hepper, E. G., Hart, C. M., Meek, R., Cisek, S., \& Sedkides, C. (2014). Narcissism and empathy in Young offenders and non-offenders. European Journal of Personality, 28(2), 201-210.

Hepper, E. G., Hart, C. M., \& Sedikides, C. (2014). Moving Narcissus: Can narcissists be empathic? Personality and Social Psychology Bulletin, 40(9), 1079-1091.

Heym, N., Firth, J., Kibowski, F., Sumich, A., Egan, V., \& Bloxsom, C. A. J. (2019). Empathy at the heart of darkness: Empathy deficits that 
bind the dark triad and those that mediate indirect relational aggression. Frontiers in Psychiatry, 10, 95.

Hogan, R. (1969). Development of an empathy scale. Journal of Consulting and Clinical Psychology, 33, 307-316.

Obhi, S. S, Hogeveen, J., Giacomin, M., \& Jordan, C. H. (2014). Automatic imitation is reduced in narcissists. Journal of Experimental Psychology: Human Perception and Performance, 40(3), 920-928.

Hogeveen, J., \& Obhi, S. S. (2013). Automatic imitation is automatic, but less so for narcissists. Experimental Brain Research, 224(4), 613621

Horvath, S., \& Morf, C. (2009). Narcissistic defensiveness: Hypervigilance and avoidance of worthlessness. Journal of Experimental Social Psychology, 45, 1252-1258.

Hwang, J. Y., Plante, T., \& Lackey, K. (2008). The development of the Santa Clara brief compassion scale: An abbreviation of Sprecher and Fehr's compassionate love scale. Pastoral Psychology, 56, 421-428.

Hyler, S. E. (1994). PDQ-4 manual. NiJo Publications.

Jauk, E., Freudenthaler, H. H., \& Neubauer, A. C. (2016). The dark triad and trait versus ability emotional intelligence: Emotional darkness differs between women and men. Journal of Individual Differences, $37(2), 112-118$.

Johnson, J. A. (2014). Measuring thirty facets of the five factor model with a 120-item public domain inventory: Development of the IPIPNEO-120. Journal of Research in Personality, 51, 78-89.

Jolliffe, D., \& Farrington, D. P. (2006). Development and validation of the basic empathy scale. Journal of Adolescence, 29, 589-611.

Jonason, P. K., \& Kavanagh, P. (2010). The dark side of love: Love styles and the dark triad. Personality and Individual Differences, 49(6), 606-610.

Jonason, P. K., \& Krause, L. (2013). The emotional deficits associated with the dark triad traits: Cognitive empathy, affective empathy, and alexithymia. Personality and Individual Differences, 55(5), 532 537.

Jonason, P. K., \& Kroll, C. H. (2015). A multidimensional view of the relationship between empathy and the dark triad. Journal of Individual Differences, 36(3), 150-156.

Jonason, P. K., Lyons, M., Bethell, E. J., \& Rahael, R. (2013). Different routes to limited empathy in the sexes: Examining the links between the dark triad and empathy. Personality and Individual Differences, 54(5), 572-576.

Jonason, P. K., \& Webster, G. D. (2010). The dirty dozen: A concise measure of the dark triad. Psychological Assessment, 22(2), 420-432.

Jones, D. N., \& Paulhus, D. L. (2014). Introducing the short dark triad (SD3): A brief measure of dark personality traits. Assessment, 21(1), 28-41.

Kajonius, P. J., \& Dåderman, A. M. (2017). Conceptualizations of personality disorders with the five factor model-count and empathy traits. International Journal of Testing, 17(2), 141-157.

Kessler, H., Bayerl, P., Deighton, R. M., \& Traue, H. C. (2002). Facially expressed emotion labelling (feel): Pc-gestutzter test zur emotions erkennung. Verhaltenstherapie und Verhaltensmedizin, 23, 297-306.

Kinderman, P., Dunbar, R., \& Bentall, R. P. (1998). Theory-of-mind deficits and causal attributions. British Journal of Psychology, 89, 191-204.

Kittel, A. F. D., Olderbak, S., \& Wilhelm, O. (2021). Sty in the Mind's eye: A meta-analytic investigation of the Nomological network and internal consistency of the "Reading the mind in the eyes" test. Assessment. https://doi.org/10.1177/1073191121996469.

Kojonius, P. J., \& Bjorkman, T. (2020). Individuals with dark traits have the ability but not the disposition to empathize. Personality and Individual Differences, 155, 109716.

Konrath, S., Corneille, O., Bushman, B. J., \& Luminet, O. (2014). The relationship between narcissistic exploitativeness, dispositional empathy, and emotion recognition abilities. Journal of Nonverbal Behavior, 38(1), 129-143.
Krizan, Z., \& Herlache, A. D. (2018). The narcissism Spectrum model: A synthetic view of narcissistic personality. Personality and Social Psychology Review, 22(1), 3-31.

Lachowicz-Tabaczek, K., Lewandowska, B., Kochan-Wójcik, M., Andrzejewska, B. E., \& Juszkiewicz, A. (2019). Grandiose and vulnerable narcissism as predictors of the tendency to objectify other people. Current Psychology. https://doi.org/10.1007/s12144-01900569-3.

Lannin, D. G., Guyll, M., Krizan, Z., Madon, S., \& Cornish, M. (2014). When are grandiose and vulnerable narcissists least helpful? Personality and Individual Differences, 56, 127-132.

Lee, S. A., \& Gibbons, J. A. (2017). The dark triad and compassion: Psychopathy and narcissism's unique connections to observed suffering. Personality and Individual Differences, 116, 336-342.

Leunissen, J. M., Sedikides, C., \& Wildschut, T. (2017). Why narcissists are unwilling to apologize: The role of empathy and guilt. European Journal of Personality, 31(4), 385-403.

Lietz, C. A., Gerdes, K. E., Sun, F., Geiger, J. M., Wagaman, M. A., \& Segal, E. A. (2011). The empathy assessment index (EAI): A confirmatory factor analysis of a multidimensional model of empathy. Journal of the Society for Social Work and Research, 2(2), 104-124.

Lishner, D., Hong, P. Y., Jiang, L., Vitacco, M. J., \& Neumann, C. S. (2015). Psychopathy, narcissism, and borderline personality: A critical test of the affective empathy-impairment hypothesis. Personality and Individual Differences, 86, 257-265.

Lishner, D. A., Vitacco, M. J., Hong, P. Y., Mosely, J., Miska, K., \& Stocks, E. L. (2012). Evaluating the relation between psychopathy and affective empathy: Two preliminary studies. International Journal of Offender Therapy and Comparative Criminology, 56, 1161-1181.

Lobbestael, J., de Bruin, A., Kok, E., \& Voncken, M. (2016). Through rose coloured glasses: An empirical test of narcissistic overestimation. Personality and Mental Health, 10, 305-316.

Loranger, A. W. (1999). International personality disorder examination (IPDE): DSM-IV and ICD-10 modules. Psychological Assessment Resources.

Lowicki, P., \& Zajenkowski, M. (2017). No empathy for people nor for god: The relationship between the dark triad, religiosity and empathy. Personality and Individual Differences, 115, 169-173.

MacCann, C., \& Roberts, R. D. (2008). New paradigms for assessing emotional intelligence: Theory and data. Emotion, 8, 540-551.

Magidson, J. F., Collado-Rodriguez, A., Madan, A., Perez-Camoirano, N. A., Galloway, S. K., Borckardt, J. J., Campbell, W. K., \& Miller, J. D. (2012). Addressing narcissistic personality features in the context of medical care: Integrating diverse perspectives to inform clinical practice. Personality Disorders, Theory, Research, and Treatment, 3(2), 196-208.

Marcoux, L. A., Michon, P. E., Lemelin, S., Voisin, J. A., VachonPresseau, E., \& Jackson, P. L. (2014). Feeling but not caring: Empathic alteration in narcissistic men with high psychopathic traits. Psychiatry Research, 224(3), 341-348.

Margolis, H. D., \& Thomas, V. A. (1980). The measurement of narcissism in adolescents with and without behavioral and emotional disabilities. Unpublished master's thesis, United States International University, San Diego, CA.

Marissen, M. A., Deen, M. L., \& Franken, I. H. (2012). Disturbed emotion recognition in patients with narcissistic personality disorder. Psychiatry Research, 198(2), 269-273.

Martins, A. T., Ros, A., Valerio, L., \& Faisca, L. (2019). Basic emotion recognition according to clinical personality traits. Current Psychology, 38(3), 879-889.

Mayer, J. D., \& Salovey, P. (1997). What is emotional intelligence? In P. Salovey \& D. J. Sluyter (Eds.), Emotional development and emotional intelligence: Educational implications (p. 3-34). Basic Books. 
Mayer, J. D., Salovey, P., Caruso, D. R., \& Sitarenios, G. (2003). Measuring emotional intelligence with the MSCEIT V2.0. Emotion, 3, 97-105.

McClure, E. B. (2000). A meta-analytic review of sex differences in facial expression processing and their development in infants, children, and adolescents. Psychological Bulletin, 126, 424-453.

McCullough, M. E., Emmons, R. A., Kilpatrick, S. D., \& Mooney, C. N. (2003). Narcissists as "victims": The role of narcissism in the perception of transgressions. Personality and Social Psychology Bulletin, 29(7), 885-893.

McGregor, I., Nail, P. R., Kocalar, D., \& Haji, R. (2013). I'm OK, I'm OK: Praise makes narcissists with low implicit self-esteem indifferent to the suffering of others. Personality and Individual Differences, 55(6), 655-659.

Mehrabian, A., \& Epstein, N. (1972). A measure of emotional empathy. Journal of Personality, 40, 525-543.

Meltzoff, A. N. (2007). 'Like me': A foundation for social cognition. Developmental Science, 10(1), 126-134.

Miller, J. D., \& Campbell, W. K. (2008). Comparing clinical and socialpersonality conceptualizations of narcissism. Journal of Personality, 76, 449-476.

Miller, J. D., Campbell, W. K., \& Pilkonis, P. A. (2007). Narcissistic personality disorder: Relations with distress and functional impairment. Comprehensive Psychiatry, 48(2), 170-177.

Miller, J. D., Gentile, B., \& Campbell, W. K. (2013). A test of the construct validity of the five-factor narcissism inventory. Journal of Personality Assessment, 95, 377-387.

Miller, J. D., Lynam, D. R., McCain, J. L., Few, L. R., Crego, C., Widiger, T. A., \& Campbell, W. K. (2016). Thinking structurally about narcissism: An examination of the five-factor narcissism inventory and its components. Journal of Personality Disorders, 30(1), 1-18.

Miller, J. D., Lynam, D. R., Rolland, J. P., De Fruyt, F., Reynolds, S. K., Pham-Scottez, A., Baker, S. R., \& Bagby, R. M. (2008). Scoring the DSM-IV personality disorders using the five-factor model: Development and validation of normative scores for north American, French, and Dutch-Flemish samples. Journal of Personality Disorders, 22, 433-450.

Miller, J. D., Lynam, D. R., Vize, C., Crowe, M., Sleep, C., MaplesKeller, J. L., Few, L. R., \& Campbell, W. K. (2018). Vulnerable narcissism is (mostly) a disorder of neuroticism. Journal of Personality, 86, 1467-1494.

Millon, T., Millon, C., Davis, R., \& Grossman, S. (2009). MCMI-III: Millon clinical multiaxial inventory manual (4th ed.). Pearson Education.

Morf, C. C., \& Rhodewalt, F. (2001). Unraveling the paradoxes of narcissism: A dynamic self-regulatory processing model. Psychological Inquiry, 12, 177-196.

Nagler, U., Reiter, K., Furtner, M., \& Rauthmann, J. (2014). Is there a dark intelligence? Emotional intelligence is used by dark personalities to emotionally manipulate others. Personality and Individual Differences, 65, 47-52.

Nakayama, R., \& Nakaya, M. (2006). Developmental transformation of narcissism in adolescence. Japanese Journal of Educational Psychology, 54(2), 188-198.

Oakley, B. F., Brewer, R., Bird, G., \& Catmur, C. (2016). Theory of mind is not theory of emotion: A cautionary note on the Reading the mind in the eyes test. Journal of Abnormal Psychology, 125(6), 818-823.

Ogrodniczuk, J. S., Piper, W. E., Joyce, A. S., Steinberg, P. I., \& Duggal, S. (2009). Interpersonal problems associated with narcissism among psychiatric outpatients. Journal of Psychiatric Research, 43(9), 837-842.

Oliveira, C. M., \& Levine, T. R. (2008). Lie acceptability: A construct and measure. Communication Research Reports, 25, 282-288.

Oltmanns, J. R., \& Widiger, T. A. (2018). Assessment of fluctuation between grandiose and vulnerable narcissism: Development and initial validation of the FLUX scales. Psychological Assessment, $30(12), 1612-1624$.

Onley, M., Veselka, L., Schermer, J. A., \& Vernon, P. A. (2013). Survival of the scheming: a genetically informed link between the dark triad and mental toughness. Twin Research and Human Genetics, 16(6), $1087-1095$.

Pajevic, M., Vukosavljevic-Gvozden, T., Stevanovic, N., \& Neumann, C. S. (2018). The relationship between the dark tetrad and a twodimensional view of empathy. Personality and Individual Differences, 123, 125-130.

Papageorgiou, K. A., Denovan, A., \& Dagnall, N. (2019). The positive effect of narcissism on depressive symptoms through mental toughness: Narcissism may be a dark trait but it does help with seeing the world less grey. European Psychiatry, 55, 74-79.

Park, S. W., \& Colvin, C. R. (2015). Narcissism and other-derogation in the absence of ego threat. Journal of Personality, 83(3), 334-345.

Paulus, C. (2009). Der Saarbrücker Persönlichkeitsfragebogen SPF (IRI) zur Messung von Empathie. Universität des Saarlandes: Fachrichtung Erziehungswissenschaft. Retrieved from http:// psydok.sulb.uni-saarland.de/volltexte/2009/2363/.

Pellecchia, G., Moroni, F., Carcione, A., Colle, L., Dimaggio, G., Nicolò, G., Semerari, A., \& Procacci, M. (2015). Metacognition assessment interview: Instrument description and factor structure. Clinical Neuropsychiatry, 12, 156-167.

Petrides, K. V., \& Furnham, A. (2006). The role of trait emotional intelligence in a gender-specific model of organizational variables. Journal of Applied Social Psychology, 36, 552-569.

Petrides, K. V., Vernon, P. A., Schermer, J. A., \& Veselka, L. (2011). Trait emotional intelligence and the dark triad traits of personality. Twin Research and Human Genetics, 14(1), 35-41.

Pincus, A. L., Ansell, E. B., Pimentel, C. A., Cain, N. M., Wright, A. G. C., \& Levy, K. N. (2009). Initial construction and validation of the pathological narcissism inventory. Psychological Assessment, 21(3), 365-379.

Porter, S., Bhanwer, A., Woodworth, M., \& Black, P. J. (2014). Soldiers of misfortune: An examination of the dark triad and the experience of schadenfreude. Personality and Individual Differences, 67, 64 68.

Premack, D., \& Woodruff, G. (1978). Does the chimpanzee have a theory of mind? Behavioral and Brain Sciences, 1(4), 515-526.

Preston, S. D., \& De Waal, F. B. M. (2002). Empathy: Its ultimate and proximate bases. Behavioral and Brain Sciences, 25(1), 1-20.

Raskin, R. N., \& Hall, C. S. (1979). A narcissistic personality inventory. Psychological Reports, 45, 590.

Reniers, R. L., Corcoran, R., Drake, R., Shryane, N. M., \& Völlm, B. A. (2011). The QCAE: a questionnaire of cognitive and affective empathy. Journal of Personality Assessment, 93, 84-95.

Riggio, R. E., \& Carney, D. R. (2003). Social skills inventory manual (2nd ed.). Mind Garden.

Ritter, K., Dziobek, I., Preißler, S., Rüter, A., Vater, A., Fydrich, T., Lammers, C. H., Heekeren, H. R., \& Roepke, S. (2011). Lack of empathy in patients with narcissistic personality disorder. Psychiatry Research, 187(1), 241-247.

Rogoza, R., Żemojtel-Piotrowska, M., Kwiatkowska, M. M., \& Kwiatkowska, K. (2018). The bright, the dark, and the blue face of narcissism: The Spectrum of narcissism in its relations to the Metatraits of personality, self-esteem, and the Nomological network of shyness, loneliness, and empathy. Frontiers in Psychology, 9, 343.

Romero-Martínez, A., Lila, M., \& Moya-Albiol, L. (2016). Empathy impairments in intimate partner violence perpetrators with antisocial and borderline traits: A key factor in the risk of recidivism. Violence and Victims, 2, 347-360.

Ronningstam, E. (2005). Identifying and understanding the narcissistic personality. Oxford University Press. 
Ronningstam, E. (2010). Narcissistic personality disorder: A current review. Current Psychiatry Reports, 12, 68-75.

Sabouri, S., Gerber, M., Sadeghi Bahmani, D., Lemola, S., Clough, P. J., Kalak, N., Shamsi, M., Holsboer-Trachsler, E., \& Brand, S. (2016). Examining dark triad traits in relation to mental toughness and physical activity in young adults. Neuropsychiatric Disease and Treatment, 12, 229-235.

Schimmenti, A., Jonason, P. K., Passanisi, A., La Marca, L., Di Dio, N., \& Gervasi, A. M. (2019). Exploring the dark side of personality: Emotional awareness, empathy, and the dark triad traits in an Italian sample. Current Psychology, 38(1), 100-109.

Schotte, C. K. W., \& de Doncker, D. (1994). ADP-IV Questionnaire. University Hospital Antwerp, Antwerp.

Schutte, N. S., Malouff, J. M., Hall, L. E., Haggerty, D. J., Cooper, J. T., Golden, C. J., \& Dornheim, L. (1998). Development and validation of a measure of emotional intelligence. Personality and Individual Differences, 25, 167-177.

Shamay-Tsoory, S. G., \& Aharon-Peretz, J. (2007). Dissociable prefrontal networks for cognitive and affective theory of mind: a lesion study. Neuropsychologia, 45(13), 3054-3067.

Shamay-Tsoory, S. G., Aharon-Peretz, J., \& Perry, D. (2009). Two systems for empathy: a double dissociation between emotional and cognitive empathy in inferior frontal gyrus versus ventromedial prefrontal lesions. Brain, 132(3), 617-627.

Sheehan, D. V., Lecrubier, Y., Sheehan, K. H., Amorim, P., Janavs, J., Weiller, E., Hergueta, T., Baker, R., \& Dunbar, G. C. (1998). The Mini-international neuropsychiatric interview (M.I.N.I.): The development and validation of a structured diagnostic psychiatric interview for DSM-IV and ICD-10. Journal of Clinical Psychiatry, 59(S1), 34-57.

Silvera, D., Martinussen, M., \& Dahl, T. I. (2001). The Tromsø social intelligence scale: A self-report measure of social intelligence. Scandinavian Journal of Psychology, 42, 313-319.

Śmieja, M., Orzechowski, J., \& Stolarski, M. (2014). TIE: An ability test of emotional intelligence. PLoS One, 9(7), e103484.

Smith, H. C. (1973). Sensitivity training: The scientific understanding of individuals. McGraw-Hill.

Solomon, R. S. (1982). Validity of the MMPI narcissistic personality disorder scale. Psychological Reports, 50, 463-466.

Stellwagen, K. K., \& Kerig, P. K. (2013a). Ringleader bullying: Association with psychopathic narcissism and theory of mind among child psychiatric inpatients. Child Psychiatry \& Human Development, 44(5), 612-620.

Stellwagen, K. K., \& Kerig, P. K. (2013b). Dark triad personality traits and theory of mind among school-age children. Personality and Individual Differences, 54(1), 123-127.

Stinson, F. S., Dawson, D. A., Goldstein, R. B., Grant, B. F., Chou, S. P., Goldstein, R. B., Huang, B., Stinson, F. S., Saha, T. D., Smith, S. M., Dawson, D. A., Pulay, A. J., Pickering, R. P., \& Ruan, W. J. (2008). Prevalence, correlates, disability, and comorbidity of DSMIV narcissistic personality disorder: Results from the wave 2 National Epidemiologic Survey on alcohol and related conditions. Journal of Clinical Psychiatry, 69(7), 1033-1045.

Stone, V. E., Baron-Cohen, S., \& Knight, R. T. (1998). Frontal lobe contributions to theory of mind. Journal of Cognitive Neuroscience, 10(5), 640-656.

Sutton, J., Smith, P. K., \& Swettenham, J. (1999). Social cognition and bullying: Social inadequacy or skilled manipulation? British Journal of Developmental Psychology, 17, 435-450.

Takšić, V. (2001). Upitnici emocionalne kompetentnosti (inteligencije). In K. Lacković-Grgin \& Z. Penezić (Eds.), Zbirka psihologijskih mjernih instrumenata. Faculty of Philosophy.

Tottenham, N., Tanaka, J. W., Leon, A. C., \& Mc- Carry, T., Nurse, M., Hare, T. A., \& Nelson, C. (2009). The NimStim set of facial expressions: Judgments from untrained research participants. Psychiatry Research, 168, 242-249.

Turner, I. N., Foster, J. D., \& Gregory, W. (2019). The dark Triad's inverse relations with cognitive and emotional empathy: Highpowered tests with multiple measures. Personality and Individual Differences, 139, 1-6.

Twenge, J. M., \& Foster, J. D. (2010). Birth cohort increases in narcissistic personality traits among American college students 19822009. Social Psychology and Personality Science, 1, 99-106.

Urbonaviciute, G., \& Hepper, E. G. (2020). When is narcissism associated with low empathy? A meta-analytic review. Journal of Research in Personality, 89, 104036.

Vonk, J., Zeigler-Hill, V., Ewing, D., \& Mercer, S. (2015). Mindreading in the dark: Dark personality features and theory of mind. Personality and Individual Differences, 87, 50-54.

Vonk, J., Zeigler-Hill, V., Mayhew, P., \& Mercer, S. (2013). Mirror, mirror on the wall, which form of narcissist knows self and others best of all? Personality and Individual Differences, 54(3), 396-401.

Wai, M., \& Tiliopoulos, N. (2012). The affective and cognitive empathic nature of the dark triad of personality. Personality and Individual Differences, 52(7), 794-799.

Watson, P. J., Grisham, S. O., Trotter, M. V., \& Biderman, M. D. (1984). Narcissism and empathy: Validity evidence for the narcissistic personality inventory. Journal of Personality Assessment, 48(3), 301305.

Watson, P. J., \& Morris, R. J. (1991). Narcissism, empathy and social desirability. Personality and Individual Differences, 12(6), 575579.

Weise, K. L., \& Tuber, S. (2004). The self and object representations of narcissistically disturbed children - an empirical investigation. Psychoanalytic Psychology, 21(2), 244-258.

Westen, D., Lohr, N., Silk, K., Kerber, K., \& Goodrich, S. (1985). Object relations and social cognition TAT scoring manual. University of Michigan Press.

Wiehe, V. R. (2003). Empathy and narcissism in a sample of child abuse perpetrators and a comparison sample of foster parents. Child Abuse and Neglect, 27(5), 541-555.

Wink, P. (1991). Two faces of narcissism. Journal of Personality and Social Psychology, 61, 590-597.

Wojciszke, B., \& Baryla, W. (2005). Skale do pomiaru nastroju i szes'ciu emocji. Czasopismo Psychologiczne, 11, 31-47.

Young, A., Perrett, D. I., Calder, A., Sprengelmeyer, R. H., \& Ekman, P. (2002). Facial expressions of emotion: Stimuli and test (FEEST).

Zajenkowski, M., Maciantowicz, O., Szymaniak, K., \& Urban, P. (2018). Vulnerable and grandiose narcissism are differentially associated with ability and trait emotional intelligence. Frontiers in Psychology, 9, 1606.

Zeigler-Hill, V., \& Besser, A. (2013). A glimpse behind the mask: Facets of narcissism and feelings of self-worth. Journal of Personality Assessment, 95(3), 249-260.

Zeigler-Hill, V., Myers, E. M., \& Clark, C. B. (2010). Narcissism and self-esteem reactivity: The role of negative achievement events. Journal of Research in Personality, 44, 285-292.

Zhang, W., Zou, H., Wang, M., \& Finy, S. (2015). The role of the dark triad traits and two constructs of emotional intelligence on loneliness in adolescents. Personality and Individual Differences, 75, 74-79.

Zondag, H. J. (2007). Unconditional giving and unconditional taking: Empathy and narcissism among pastors. Journal of Pastoral Care \& Counselling, 61(1-2), 85-97.

Publisher's Note Springer Nature remains neutral with regard to jurisdictional claims in published maps and institutional affiliations. 